NIPER-648

Distribution Categery UC-122

NI PER --648

Special Core Analyses and Relative Permeability

DE 93000119

Measurements on Almond Formation Reservoir Rocks

Topical Report

By

Dan Maloney

Kevin Doggett

Alan Brinkmeyer

February 1993

Work Performed Under Cooperative Agreement No. DE-FC22-83FE60149

Prepared for

U. S. Department of Energy

Assistant Secretary for Fossil Energy

Rhonda P. Lindsey, Project Manager

Bartlesville Project Office

P. O. Box 1398

Bartlesville, OK 74005

Prepared by

IIT Research Institute

National Institute for Petroleum and Energy Research

P.O. Box 2128

Bartlesville, OK 74005

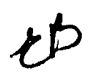




\section{TABLE OF CONTENTS}

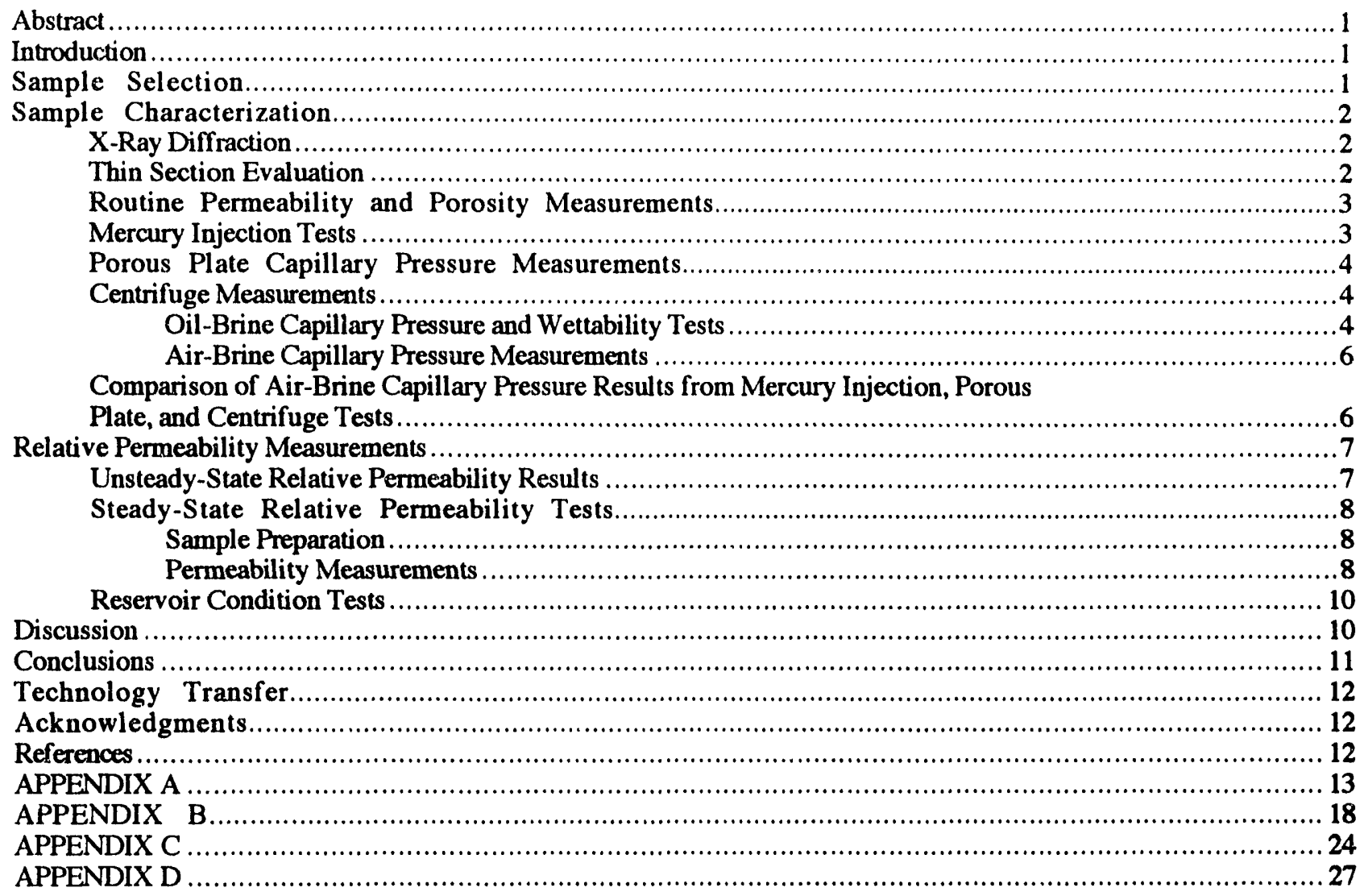

TABLES

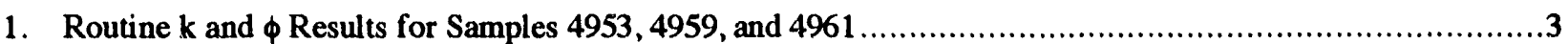

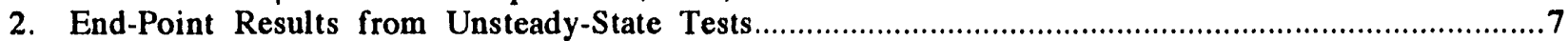

\section{ILLUSTRATIONS}

1. Grain diameter distributions from sample 4953 and 4961 thin-section analyses .....................................

2. Log-differential intrusion vs. diameter results for plug 4953 from mercury intrusion test results ...................4

3. Log-log hyperbolic plot of mercury injection data for plug 4953 following techniques described by Thomeer ${ }^{2}$ and Swanson $^{3}$

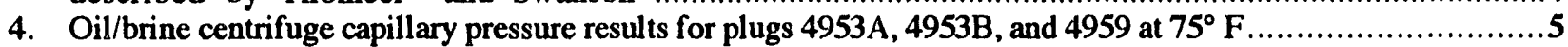

5. Comparison of average and face saturations from plug 4961 oil-brine centrifuge tests at $150^{\circ} \mathrm{F}$.....

6. Oil/brine centrifuge capillary pressure results using decane and Soltrol 100 as the oil

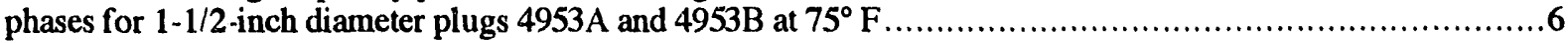

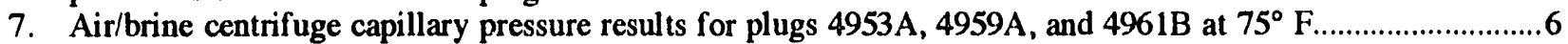

8. Comparison of air-brine capillary pressures measured mercury injection, porous plate, and centrifuge techniques for Almond formation plugs. The plug depths are shown in the legend ......................

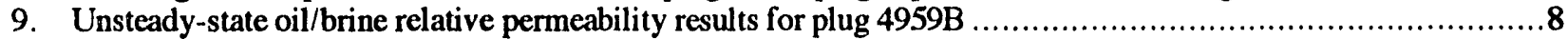

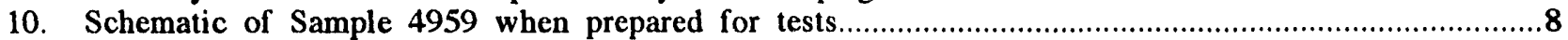

11. Steady-state gas/water relative permeability results for plug 4959 . Results are normalized with respect to $\mathrm{k}_{\mathrm{w}}=5.78 \mathrm{mD}$ at $\mathrm{S}_{\mathrm{w}}=1.000$.

12. Steady-state oil/water relative permeability results for plug 4959 . Results are normalized with respect to $\mathrm{k}_{\mathrm{w}}=5.78 \mathrm{mD}$ at $\mathrm{Sw}=1.000$ 


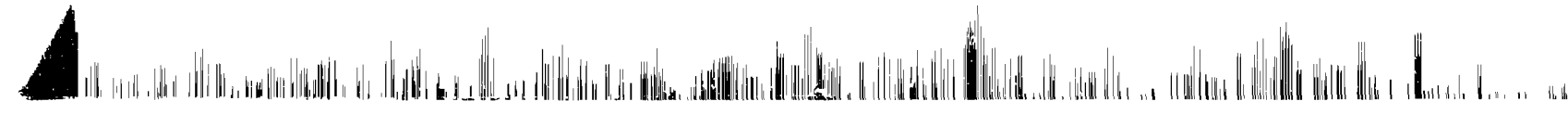

\section{ILLUSTRATIONS - Continued}

13. Gas results from a steady-state gas/oil/residual water test with plug 4959. Results are

Page normalized with respect to $k_{w}=5.78 \mathrm{mD}$ at $S_{w}=1.000$

14. Two- and three-phase brine steady-state relative permeability results for plug 4959.

Results are normalized with respect to $k_{W}=5.78 \mathrm{mD}$ at $S_{w}=1.000$

15. Two- and three-phase oil steady-state relative permeability results for plug 4959. Results

are normalized with respect to $k_{w}=5.78 \mathrm{mD}$ at $S_{w}=1.000$

16. Two- and three-phase gas steady-state relative permeability results for plug 4959.

Results are normalized with respect to $k_{w}=5.78 \mathrm{mD}$ at $S_{w}=1.000$. 


\title{
SPECIAL CORE ANALYSES AND RELATIVE PERMEABILITY MEASUREMENTS ON ALMOND FORMATION RESERVOIR ROCKS
}

\author{
By Dan Maloney, Kevin Doggett, and Alan Brinkmeyer
}

\begin{abstract}
This report describes the results from special core analyses and relative permeability measurements conducted on samples of rock from the Almond Formation in Greater Green River Basin of southwestern Wyoming. The core was from Arch Unit Well 121 of Patrick Draw field. Samples were taken from the 4,950 to $4,965 \mathrm{ft}$ depth interval.

Thin section evaluation, $\mathrm{X}$-ray diffraction, routine permeability and porosity, capillary pressure and wettability tests were performed to characterize the samples. Fluid flow capacity characteristics were measured during two-phase unsteady- and steady-state and three-phase steady-state relative permeability tests. Test results are presented in tables and graphs. Relative permeability results are compared with those of a $260-\mathrm{mD}$, fired Berea sandstone sample which was previously subjected to similar tests. Brine relative permeabilities were similar for the two samples, whereas oil and gas relative permeabilities for the Almond formation rock were higher at equivalent saturation conditions compared to Berea results.

Most of the tests described in this report were conducted at $74^{\circ} \mathrm{F}$ laboratory temperature. Additional tests are planned at $150^{\circ} \mathrm{F}$ temperature. Equipment and procedural modifications to perform the elevated temperature tests are described.
\end{abstract}

\section{Introduction}

Multiphase flow is a common phenomenon in production from petroleum reservoirs. The initial or primary production from a reservoir may include gas, oil, brine, or combinations of the three. Later during the productive life of a reservoir, two-phase flow occurs as fluid such as brine is injected into a reservoir to boost production. Finally, if enhanced oil recovery techniques are used to maximize hydrocarbon recovery, multiphase flow processes are virtually guaranteed to occur. With multiphase flow, the fluids compete for the same flow paths through the reservoir rock. The additional resistance to flow is described by normalizing permeabilities for each of the flowing phases at each fluid saturation condition with respect to a base permeability. This measurement and normalization process yields relative permeability data.

The concept of relative permeability for two-phase flow is not new. Work on developing two-phase flow relationships probably began in 1859 , and through the years techniques for using the results have been refined for estimating petroleum reservoir productivity and performance. Efforts to extend the techniques for three- phase flow began in 1941, but difficulties limited progress in this area. Three-phase flow experiments for determining relative permeability relationships are very difficult to perform. Measuring fluid saturations in a rock during three-phase steady-state flow experiments was virtually impossible until the recent advent of techniques to monitor in situ fluid saturations directly during flow experiments. Correlations have been developed to predict three-phase flow effects from twr-phase flow measurements, but such correlations are not always correct or accurate. The primary reasons for the limited knowledge with respect to threephase flow systems are the scarcity of accurate three-phase relative permeability laboratory data and laboratory measurement systems.

The objectives of this project are to improve the reliability of laboratory measurements of two- and threephase relative permeabilities for steady- and unsteady-state conditions in core samples; to investigate the influence of rock, fluid, and rock-fluid properties on two- and threephase relative permeabilities; and to expand the capabilities of measuring relative permeabilities under broader temperature and pressure conditions.

Project efforts were concentrated in two primary areas: examination of the mutual relationships among petrophysical properties and relative permeabilities; and improving the state-of-the art in three-phase measurements at higher pressure and temperature conditions. During this project year, tests were conducted on a low-permeability reservoir rock sample. In comparison with previous work to characterize and measure properties of clean, quarried sandstone rock samples, testing reservoir rock presented some interesting challenges and required many innovations in test procedures and designs.

\section{Sample Selection}

Discussions were held with project leaders of other Department of Energy sponsored NIPER projects (BE1 and BE12) to see if we could select a rock type that would also be of interest with respect to other project objectives. Several candidate formations were discussed. A decision was made to investigate some Patrick Draw field, Almond formation rock which was already available at NIPER. The core was on loan from Union Pacific Resources Company (UPRC). The Almond formation is composed of thin beds of sandstones and shales.

Core from the Arch Unit Well 120 of Patrick Draw field and literature describing the field were inspected to evaluate whether the rock would be suitable for this investigation. Patrick Draw field, a production unit of the Almond formation in the Greater Green River Basin of southwestern Wyoming has been studied by the NIPER BEl project 
team. Average reservoir, rock, and fluid characteristics reported in the literature include the following:

$\begin{array}{ll}\text { oil viscosity, } \mathrm{cP} & 0.52 \\ \text { rock porosity, } \% & 19.8 \\ \text { rock permeability, } \mathrm{mD} & 36 \\ \text { reservoir depth, } \mathrm{ft} & 5,100 \\ \text { reservoir temperature, }{ }^{\circ} \mathrm{F} & 121 \\ \text { pay thickness, } \mathrm{ft} & 20 \\ \text { field size, acres } & 16,540\end{array}$

One of the NIPER geologists from the BE1 project staff inspected core from Arch Unit 121 well and identified the reservoir-quality rock. Some attractive characteristics of the formation and rock for the BE9 project include:

A. Low formation temperature.

B. Fairly clean rock (less than $5 \%$ clay minerals).

C. Oil viscosity close to $1 \mathrm{cP}$.

D. Reservoir stress conditions that can be approximated in laboratory tests.

E. Relative permeability measurements from project BE9 would also contribute toward BE1 objectives.

Core from Patrick Draw field, Arch Unit, Well 120 was selected as the rock for the BE9 investigation. Whole core sections from 4,953,4,959, and 4,961 ft were scanned by computed tomography (CT) within their protective jackets. The cores were fairly homogeneous although 3 dimensional reconstructions of the $\mathrm{CT}$ images indicated the presence of some bedding features. The CT densities of the bedding features were slightly higher than the densities of the surro unding rock. Upon removing the rocks from their protective jackets, some silty bedding features were observed which coincided with the areas where the higher CT densities occurred.

The cores were slabbed. Plugs and other samples were cut from the core sections. Several blocks with rectangular cross sections were cut for three-phase flow experiments. Plugs with 1 inch diameters were drilled for mercury injection porosimetry and centrifuge tests. Plugs with 1.5 inch diameters were drilled for two-phase unsteady-state relative permeability tests, resistivity tests, and centrifuge capillary pressure experiments. Other pieces were obtained for thin section evaluation and for X-ray diffraction analyses.

The samples were cleaned by multiple cycles of toluene extraction followed by methanol extraction in a Dean Stark apparatus. Routine core analyses were conducted on the samples. Some samples were cleaned again because results were not consistent with those of similar plugs. Plug air permeabilities were in the $30-$ to $40-\mathrm{mD}$ range while porosities varied from 17.3 to $19 \%$.

For convenience, plug samples cut from the well core are designated by their depths in feet. For example, sample 4953 is a plug that was cut from a section of whole core from a depth of $4953 \mathrm{ft}$. The terms water and brine are used synonomously within this report to describe the test brine.

\section{Sample Characterization}

\section{$X$-Ray Diffraction}

$\mathrm{X}$-ray diffraction (XRD) analyses were conducted on rock samples from depths of 4953, 4959, and $4961 \mathrm{ft}$ to determine and compare mineralogies. XRD results show that the rocks are primarily composed of quartz (83 to $86 \%$ ), feldspars (7 to $9 \%$ ), dolomite (2 to $4 \%$ ), kaolinite (2 to $3 \%$ ), and illite or mica $(1 \%)$. The mineralogies of the three samples are very similar. Quartz and feldspar contents are nearly the sarne for each sample and for each, the ratio of potassium feldspar to plagioclase is about $1 / 1$. The only difference worthy of note is that sample 4961 has only $2 \%$ dolomite, or about half as much dolomite as sample 4953.

\section{Thin Section Evaluation}

Thin sections of rock from the Arch Unit were microscopically evaluated. The thin sections were consistent for a flood tidal delta environment with respect to lithology and diagenesis. Pore structures were primarily affected by compaction and leaching. Feldspars in the rock were leached, causing microporosity. Visual examinations of samples 4953, 4959 and 4961 indicate that they are all very similar texturally and lithologically. All three are classified as feldspathic litharenite. Macroscopic examinations reveal that 4953 is massive in appearance in contrast to 4959 and 4961 , which have bedding accented by organic matter (coaly materials in thin, often discontinuous laminae). Microporosity is abundant in all three samples because of leaching of feldspars and other less stable grains. Microporosity comprises 38 to $67 \%$ of total porosity. Although the pores at first appear to be moderately large (on the order of $150 \mu \mathrm{m}$ in diameter) when viewed by the microscope, few are really clean-many have fine networks of clay which cross the pore throats.

Textural features show that the rock has undergone grain compaction and pore size reduction. An estimated 30 to $40 \%$ of the original porosity was lost because of compaction while cement reduction accounts for only 3 to $8 \%$ of the porosity loss. Because of similarities in mineralogy, texture, proportions of microporosity and dominance of compactional processes over cementation, these three samples should behave in a similar manner with respect to fluid flow. Differences in porosities and permeabilities suggest that 4953 and 4961 will behave more similarly than 4959 , which has more obvious partitioning of the pore space by relatively greater amounts of impermeable organic laminae.

Based on the thin section evaluation, two major problems may be expected in laboratory flow experiments: 
1. The micropores are expected to trap fluids.

2. The microporosity and clay networks indicate that fluid trapping and fines migration may be problems in laboratory experiments with this rock.

Grain size frequency data were plotted on log-normal probability paper. Figure 1 shows the plotted results for samples 4953 and 4961 . The grain size data are fairly well represented by the log-normal distribution function. Median (d50) diameters for samples 4953 and 4961 are read from Fig. 1 by reading the grain diameters that correspond with the $50 \%$ passing range. These were $161 \mu \mathrm{m}$ for sample 495 and $102 \mu \mathrm{m}$ for sample 4961 .

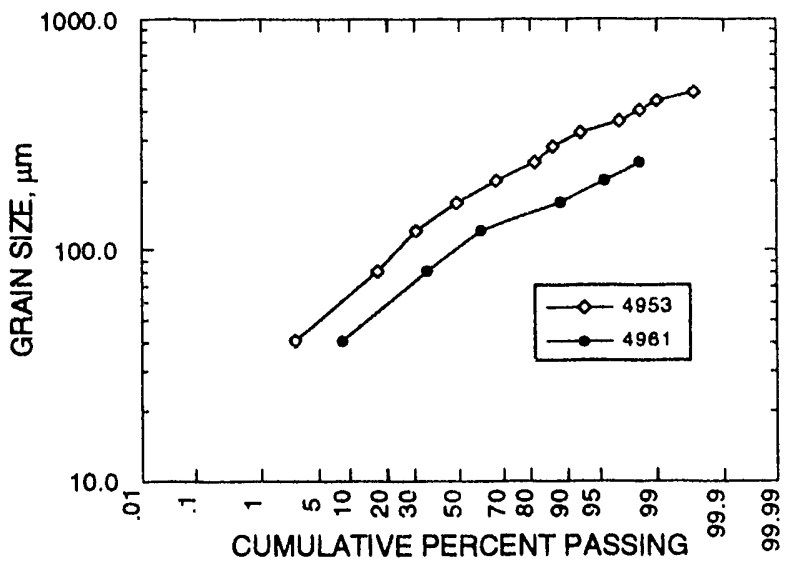

Fig. 1 Grain diameter distributions from sample 4953 and 4961 thinsection analyses.

\section{Routine Permeability and Porosity Measurements}

Air permeability and porosity measurements were conducted on plugs 4953,4959 , and 4961 . The plugs were subjected to sufficient confining pressure to seal the rubber sleeve and end-pieces against each sample to prevent gas from bypassing the rocks (100 psig). The air permeabilities were calculated from rate and pressure drop measurements using low-pressure nitrogen gas as the flowing media. Air permeabilities were not corructed for Klinkenberg slip effects. Plug bulk volumes were calculated from average length and diameter measurements.
Plug grain volumes were measured in a Boyle's law gas expansion chamber. Pore volumes were calculated by subtracting grain volumes from bulk volumes. Porosities were computed by dividing pore volumes by bulk volumes and by multiplying the result by $100 \%$. These results are shown in Table 1.

Table 1 also includes mean grain size results from thinsection point count evaluations. Estimated mean pore throat sizes are also provided in Table 1. The throat sizes were calculated using the $\log r_{50}$ equation from Table 1 of Pituman's paper. ${ }^{1}$ This equation is

$$
\log r_{50}=0.778+0.626 \operatorname{Logk}-1.205 \log \varnothing
$$

where the 2 times the $\mathrm{r}_{50}$ value is taken as the median pore throat diameter, $\log$ is the logarithm to the base $10, \mathrm{k}$ is the sample air permeability in millidarcys $(\mathrm{mD})$, and $\phi$ is the sample porosity in percent.

Because the air permeabilty and porosity measurements from routine analyses are representative of the rock under unstressed conditions, these values are useful for comparisons but are not directly representative of reservoir condition values. The permeability of sample 4959 to nitrogen gas was measured as $10.8 \mathrm{mD}$ when subjected to 1,000 psig confining pressure in a later test. Porosity versus confining pressure tests were conducted on a similar sample from the 4959 depth. This 4959 sample had a porosity of $19.1 \%$ unconfined which reduced to $18.8 \%$ when the sample was subjected to 1,000 psig confining pressure and $18.3 \%$ with 3,100 psig confining pressure. Descriptions of the confined plug pore volume measurements and the apparatus are included in appendix $A$.

\section{Mercury Injection Tests}

A mercury injection test was conducted on plug 4953 to evaluate pore throat size distributions and capillary pressure characteristics. The mercury intrusion data and useful calculations are provided in appendix B. Figure 2 shows mercury intrusion results plotted as $\log$ differential intrusion versus pore aperture diameter. From the plot, it is easy to identify that the median pore diameter is in the 1 to $10 \mu \mathrm{m}$ range and that the rock has a significant amount of microporosity. From the mercury injection data, the median pore diameter (by volume) was calculated as 1.48 $\mu \mathrm{m}$.

TABLE 1

Routine $k$ and $\varnothing$ Results for Samples 4953, 4959, and 4961

\begin{tabular}{ccccc}
\hline Sample & $\mathbf{k}, \mathbf{m D}$ & $\boldsymbol{\emptyset}, \%$ & $\begin{array}{c}\text { Mean grain size } \\
\text { from point counts, } \mu \mathrm{m}\end{array}$ & $\begin{array}{c}\text { Calculated median } \\
\text { throat size, } \mu \mathrm{m}\end{array}$ \\
\hline 4953 & 40.5 & 19.6 & 161 & 3.4 \\
4959 & 30.9 & 18.2 & 144 & 2.2 \\
4961 & 41.5 & 20.1 & 102 & 3.3 \\
\hline
\end{tabular}




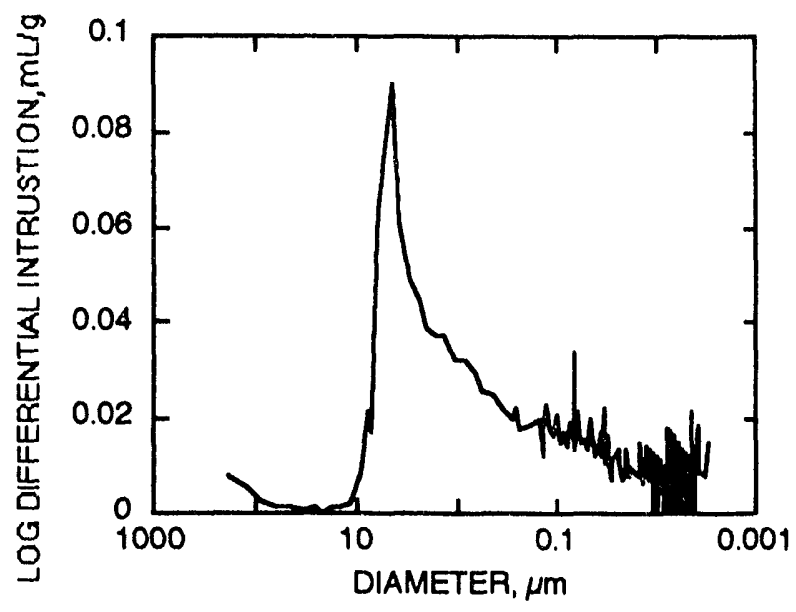

Fig. 2 Log-differential intrusion versus diameter results for plug 4953 from mercury intrusion test results.

The mercury results were used to predict gas and brine permeabilities according to techniques described by Thomeer ${ }^{2}$ and Swanson. ${ }^{3}$ The mercury injection data were plotted as capillary pressure versus mercury saturation on log paper. The mercury saturation is described as a percentage of the bulk sample volume rather than as a percentage of the pore volume. Part of the curve can be approximated with a hyperbola. A tangent to the curve with a slope of $1 \mathrm{log}$ cycle/per $\log$ cycle is used to determine a correlating parameter $\left(\mathrm{S}_{\mathrm{b}} / \mathrm{P}_{\mathrm{c}}\right)$ as shown in Fig. 3 for sample 4953 .

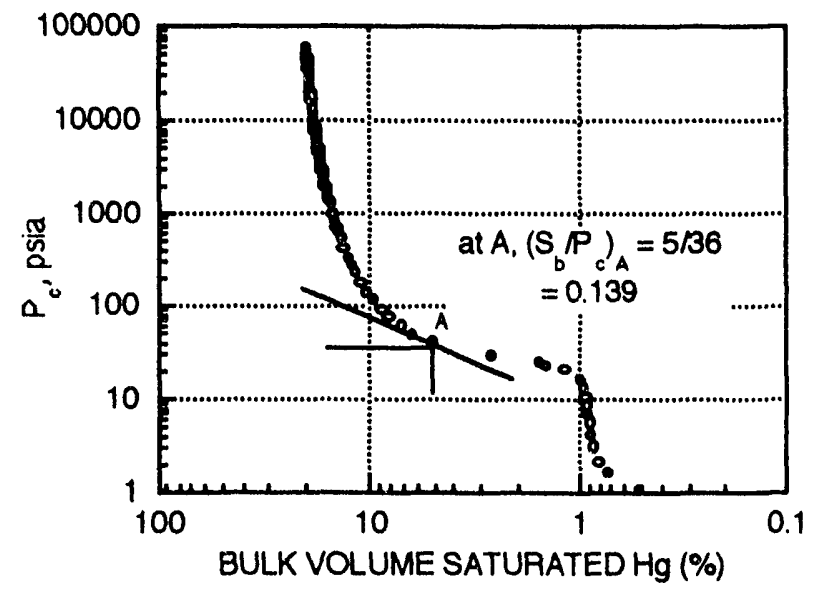

Fig. 3 Log-log hyperbollc plot of mercury injection data for plug 4953 following techniques described by Thomeer ${ }^{2}$ and Swanson 3

Swanson $^{3}$ and Juhasz ${ }^{4}$ gave correlations for air and brine permeabilities based on $\left(\mathrm{S}_{\mathrm{b}} / \mathrm{P}_{\mathrm{c}}\right)$ results from measurements on many sandstone and limestrne samples. Their relationships are:

$$
\begin{aligned}
& k_{a}=399\left(S_{b} / P_{c}\right)^{1.691} \\
& k_{w}=355\left(S_{b} / P_{c}\right)^{2.005}
\end{aligned}
$$

where subscripts ' $a$ ' and ' $w$ ' are for air and brine, permeabilities are in $\mathrm{mD}$, the mercury saturation $\left(\mathrm{S}_{b}\right)$ is percent of bulk volume, and the capillary pressure $\left(\mathrm{P}_{\mathrm{C}}\right)$ is in psi. From Fig. 3, $\mathrm{Sb}_{\mathrm{b}} / \mathrm{P}_{\mathrm{c}}$ for plug 4953 is 0.139 . Inserting this value into Eqs. 2 and 3 yields air and brine permeability predictions of 14.2 and $6.8 \mathrm{mD}$, respectively. Measured values were $40.5 \mathrm{mD}$ for the unconfined sample measured with air and $8.5 \mathrm{mD}$ for the sample measured with water using 1,000 psig confining pressure. The brine permeability prediction is in good agreement with the measured value, whereas the measured gas permeability is higher than the predicted value. Pugh and others ${ }^{5}$ provided an equation to predict brine permeabilities based on gas permeability measurements. From tests on many samples, they found:

$$
\mathrm{k}_{\mathrm{w}}=0.5386\left(\mathrm{k}_{\mathrm{g}}\right)^{1.0165}
$$

Inserting the measured brine permeability value of $8.5 \mathrm{mD}$ for plug 4953 into Eq. 4 yields a gas permeability prediction of $12.1 \mathrm{mD}$, which is similar to the value predicted by Eq. 2 . The $40.5 \mathrm{mD}$ gas permeability measured without confining pressure probably would have been considerably lower had the sample been subjected to higher stress conditions.

For comparison, from Table 1 , the gas permeability of sample 4959 was $30.9 \mathrm{mD}$ when tested unconfined. The gas and brine permeabilities of the sample with 1,000 psig confining pressure were 10.8 and $5.9 \mathrm{mD}$, respectively. These values are in better agreement with the predictions using the mercury data and Eqs. 2,3, and 4.

\section{Porous Plate Capillary Pressure Measurements}

Air-brine capillary pressures were measured with sample 4953. The brine saturated plug was placed inside a Ruska Model 1081-801 capillary pressure cell. The cell featured a porous plate of 65 psig air displacement pressure. Porous plate capillary pressure data and further descriptions are given in Table B3 of appendix B. Results are shown in Fig. 8.

\section{Centrifuge Measurements}

\section{Oil-Brine Capillary Pressure and Wettability Tests}

Several centrifuge wettability tests were conducted with plugs from depths in the 4,950 to $4,965 \mathrm{ft}$ range. The plugs were of $1 \mathrm{in}$. diameter with 1 in. lengths. The tests were conducted at $75^{\circ} \mathrm{F}$ and $150^{\circ} \mathrm{F}$ using an $\mathrm{IEC}^{\circledR}$ centrifuge. Soltrol 100 and a $2 \%$ by weight $\mathrm{KCl}$ brine were used as the test fluids.

The brine-saturated samples were placed in oil-filled centrifuge tubes and were spun at the test temperature at about 3,300 RPM for 20 hours to drive brine saturations to 
residual conditions. The volume displaced from each plug was recorded.

The first brinc-displacing-oil and second oil-displacingbrine centrifuge tests were then performed. The plugs were re-oriented as necessary between tests to maintain consistency in the direction of fluid movement. The samples tested at room temperature were spun at five centrifuge speeds ranging from about 400 to 3,300 R.PM, imposing positive (oil-displacing-brine) capillary pressures of 0.2 to $15 \mathrm{psi}$ and negative (brine-displacing-oil) capillary pressures of -0.4 to $-27 \mathrm{psi}$. Twelve hours stabilization time was allowed at each centrifuge speed before recording the volume displaced and increasing the speed to the next measurement condition. Capillary pressure and average saturation results for the three tests conducted at room temperature are shown in Fig. 4 and in Table B4 of appendix $B$. The capillary pressure versus average saturation results for the three plugs are nearly identical. The results for plug 4959 are offset from those of the 4953 plugs by about 0.05 saturation units. This offset is probably related to the limits of saturation measurement resolution and experimental error. For practical purposes, the results from the three samples can be considered to be in good agreement.

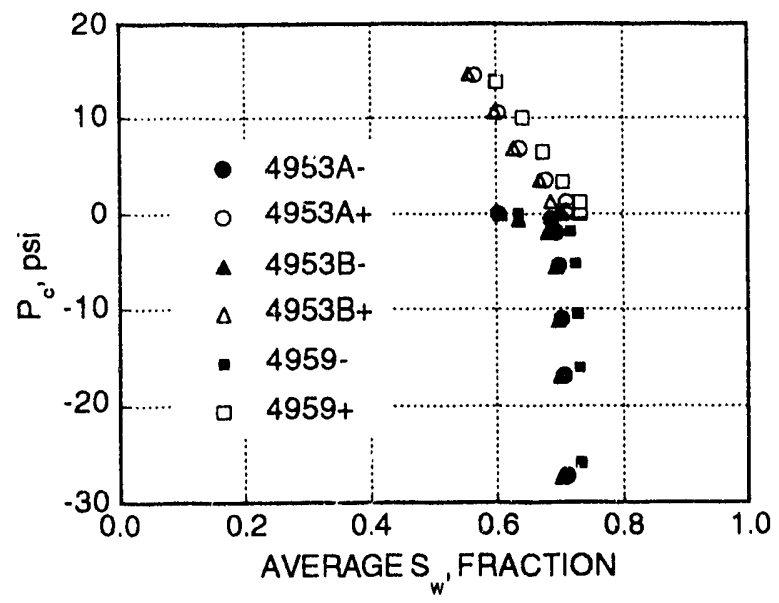

Fig. 4 Ollbrine centrifuge capillary pressure results for plugs $4953 \mathrm{~A}$, 4953B, and 4959 at $75^{\circ} \mathrm{F}$.

Tests at $150^{\circ} \mathrm{F}$ were interrupted by equipment failures. The refined oil (Soltrol 100) reacted with the silicone rubber stoppers on the high-temperature centrifuge tubes, causing errors in fluid measurements for three of the four tests that were performed. This problem was resolved by using a stopper of different chemical composition protected by a thin sheet of Teflon ${ }^{\mathrm{TM}}$ for the successful test on a plug from the 4,961-ft depth. The plug was centrifuged in a specially-designed cell to provide capillary pressure versus brine saturation results for brine-displacing-oil $\left(-P_{C}\right)$ and first and second oil-displacing-brine saturation cycles $\left(+\mathrm{P}_{\mathrm{C}}\right)$. Maximum capillary pressures of about $25 \mathrm{psi}$ for the brinedisplacing-oil and $14 \mathrm{psi}$ for the oil-displacing-brine cycles were achieved. These maximum capillary pressures were a function of the maximum centrifuge speed, the fluid densities, the plug length, and the radius of rotation. Capillary pressure and average saturation results for the successful test at 151$)^{\circ} \mathrm{F}$ are shown in Fig. 5 and in Table B4 of appendix B. Techniques for correcting the raw data for temperature-dependent volumetric expansion and contraction between centrifuge cycles are described in appendix B.

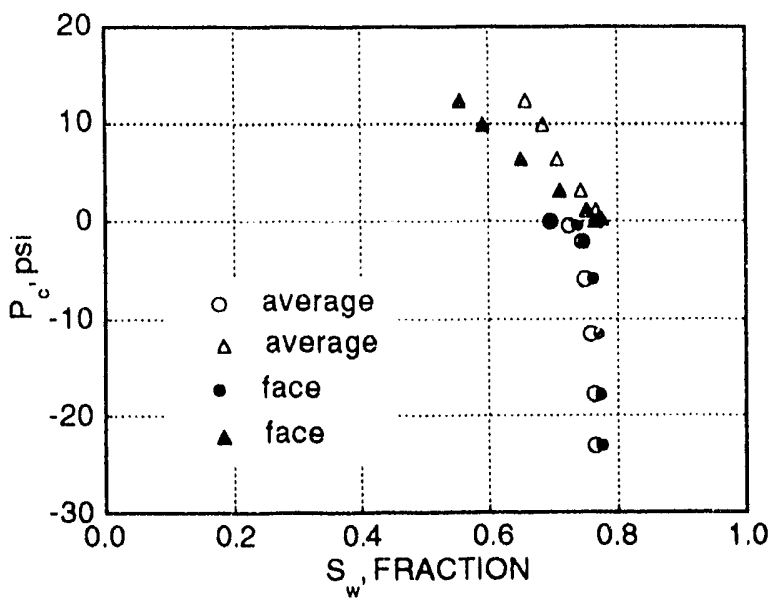

Fig 5 Comparison of average and face saturations from plug 4961 oll-brine centrifuge tests at $150^{\circ} \mathrm{F}$.

Results from the plug $4961 \mathrm{~B}$ test at $150^{\circ} \mathrm{F}$ follow the same trends as those of the three plugs tested at $75^{\circ} \mathrm{F}$. The brine saturations for all of the $150^{\circ} \mathrm{F}$ measurements are about 0.075 saturation units higher than the $75^{\circ} \mathrm{F}$ measurements on the 4,953 samples and are about 0.04 saturation units higher than the $75^{\circ} \mathrm{F}$ measurements on the 4959 sample. The effect of temperature appears to have been primarily a shift in the curves in the direction of higher water saturation while the shapes of the curves remained the same.

The capillary pressure and average saturation data were used to calculate USBM wettability indices. The method used to determine the wettability index was a truncated method where the areas under the $P_{c}$ versus $S_{W}$ are cut-off at the same capillary pressure values for the drainage and imbibition curves. Wettability indices ranging from 0.96 to 1.03 were obtained for the three samples tested at ambient temperature. The sample tested at $150^{\circ} \mathrm{F}$ had a calculated wettability index of 0.74 . These values are indicative of water-wet rock.

Average plug saturations are used in wettability calculations, whereas face saturations are considered more accurate to represent capillary pressure data in engineering calculations. Figure 5 also shows a comparison of average and face saturations for plug 4961 from the $150^{\circ} \mathrm{F}$ test. Face saturations were calculated using the Hassler Brunner technique described in appendix $B$.

Another capillary pressure experiment was conducted using a Beckman ${ }^{\circledR}$ centrifuge with two 1-1/2-inch diameter plugs in which Soltrol 100 (a refined product of Phillips Petroleum Company) was used as the oil phase with one plug while n-decane was used with the other plug. These 
tests were performed because one member of the research team questioned the wetting properties of the Soltrol oil. The drainage and imbibition capillary pressures versus average saturation results for the two plugs were nearly identical as shown in Fig. 6. Soltrol 100 and n-decane are equally nonreactive with respect to this rock.

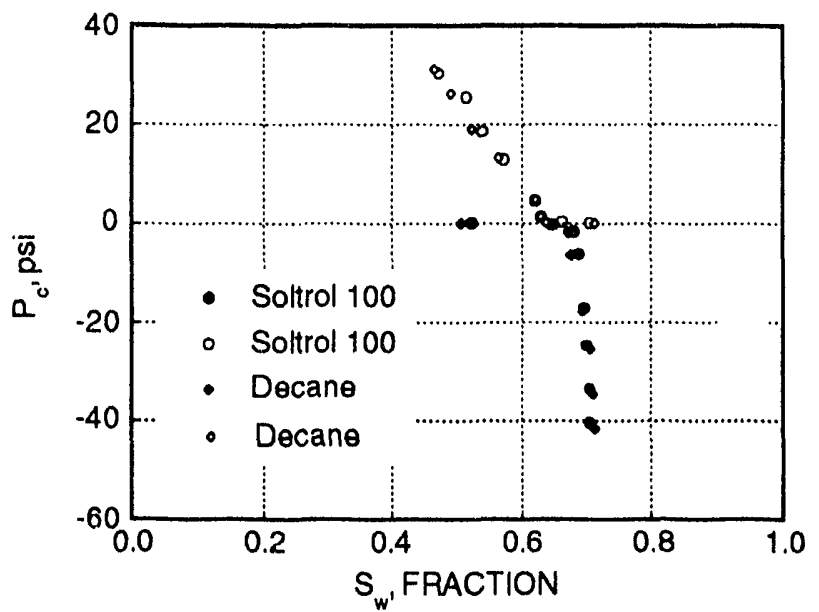

Fig. 6 Ollbrine centrifuge capillary pressure results using decane and Soltrol 100 as the ofl phases for 1 1/2-inch diameter plugs $4953 \mathrm{~A}$ and $4953 \mathrm{~B}$ at $75^{\circ} \mathrm{F}$.

As shown Figs. 4 and 5, average residual brine saturations below about $60 \%$ were not attainable with the IEC ${ }^{\circledR}$ centrifuge. Higher centrifuge speeds (3,800 vs. $3,300)$ and greater plug lengths (1.25-inch vs. 1-inch) resulted in lower resiculua brine saturations (about $50 \%$ ) for the plugs that w'se tested in the Beckman ${ }^{\circledR}$ centrifuge (Fig. 6). It is evident trom Figs. 4 thru 6 that there is appreciable brine production with rotation speed even at the end of the positive $\mathrm{P}_{\mathrm{C}}$ cycle. An ultracentrifuge would have been a better instrument for testing these low permeability, water-wet rocks. Using an ultracentrifuge capable of imposing capillary pressures to $200 \mathrm{psi}$, more accurate capillary pressure results and calculated wettability indices could be obtained near the residual satuation portions of the curves. Likewise, termination of brine production with increasing capillary pressure would eliminate the need for the truncation method used in the calculation of wettability indices.

Although the data obtained limited by equipment constraints, one can ascertain sume important qualitative characteristics from the wettability tests performed:

1. There "-as no detectable difference in reactivity of the rock to decarre or Soltrol 100.

2. The rocks are all strongly water wet as can be seen from the large areas under the oil-displacing-brine curves (in comparison to the smaller areas above the brinedisplacing-oil curves) and from the inability to obtain lower residual brine saturations.

3. There appears to be a shift towards lower residual brine saturation between the first and second oil-displacing- brine cycles (Figs.1-5). This hysteresis effect has been noted previously in water-wet $700 \mathrm{mD}$ fired Berea sandstone. ${ }^{6}$

\section{Air-Brine Capillary Pressure Measurements}

Three centrifuge air/brine capillary pressure tests were conducted with plugs from depths in the 4,950 to $4,965 \mathrm{ft}$ range. The plugs were of 1 -inch diameter with 1 -inch lengths. The tests were conducted at $75^{\circ} \mathrm{F}$ with the IEC ${ }^{\circledR}$ centrifuge. A $2 \%$ by weight $\mathrm{KCl}$ in water solution served as the brine phase.

The brine-saturated samples were placed in centrifuge tubes and spun at five centrifuge speeds ranging from about 400 to 3,000 RPM, imposing capillary pressures of 0.9 to 52 psi. Four hours stabilization time was allowed at each centrifuge speed before recording the volume displaced and increasing the speed to the next measurement condition. There was very good agreement between the three tests as can be seen in Fig. 7. Figure 7 was constructed using average rather than face saturations. These results are also provided in Table B5 in appendix B. Residual brine saturations of 50 to $55 \%$ were attained at maximum capillary pressures of about 50 psi. End-face saturations were calculated using the Hassler-Brunner method described in appendix B. Capillary pressure versus end-face saturation results for plug $4961 \mathrm{~B}$ are shown in Fig. 8.

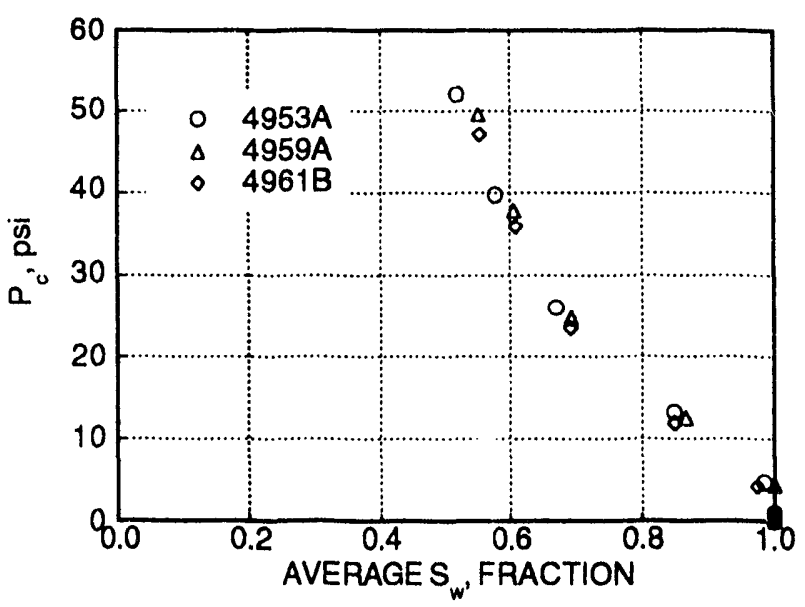

Fig. 7 Air/brine centrifuge capillary pressure results for plugs $4953 \mathrm{~A}, 4959 \mathrm{~A}$, and $4961 \mathrm{~B}$ at $75^{\circ} \mathrm{F}$.

\section{Comparison of Air-Brine Capillary Pressure Results from Mercury Injection, Porous Plate, and Centrifuge Tests}

Air-brine capillary pressure results were calculated from the mercury intrusion data using Eq. B3 of appendix B. The calculated results were compared with the results from an air-brine porous plate experiment and with centrifuge capillary pressure versus end-face saturation results. While the data trends were similar, the porous plate data appeared to start with an $85 \%$ water saturation for $P_{C}=0$, whereas 
that of mercury was approximately 95\%. To better compare the shapes of the curves, all porous plate saturations were adjusted by adding 0.10 saturation fraction units to the measured saturations. Results are shown in Fig. 8. The air-brine capillary pressures calculated from the mercury intrusion data are in very good agreement with the 'corrected' porous plate results and with the centrifuge capillary pressure versus end-face saturation data.

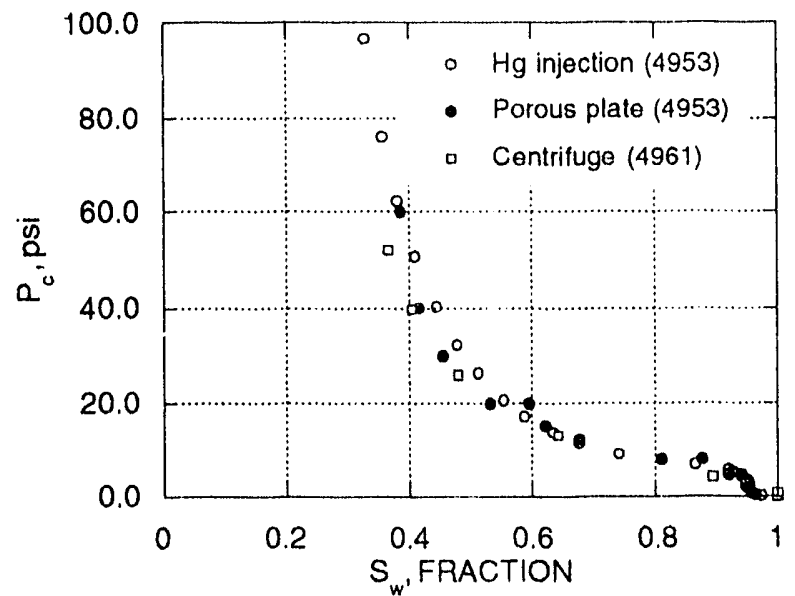

Fig. 8 Comparison of air-brine capillary pressures measured mercury injection, porous plate, and centrifuge techniques for Alnond Formation plugs. The plug depths are shown in the legend.

Relative Permeability Measurements

$$
\text { Unsteady-State } \begin{gathered}
\text { Relative Permeability } \\
\text { Results }
\end{gathered}
$$

Unsteady-state relative permeability tests were conducted on 1.5-inch-diameter by 2.5 -inch-long plugs of rock from the three depth intervals. Test fluids were a 1-cP viscosity brine containing $2 \%$ by weight potassium chloride and a mineral oil of 21 cP viscosity. The test temperature was $74^{\circ} \mathrm{F}$. The plugs were subjected to 1,000 psig confining pressure. The permeability of each dry plug was measured with nitrogen gas. Brine permeabilities were measured after saturating the plugs with brine. The plugs were oil flooded to residual water saturation conditions in preparation for waterflood tests. Constant rate waterflood tests were conducted with injection rates of 40 or 65 $\mathrm{mL} / \mathrm{hr}$. Two of the plugs were also tested using constant pressure techniques.

Table 2 provides a summary of some of the end-point results from the tests. For each plug, brine absolute permeabilities were lower than absolute permeabilities to gas. The brine permeabilities under conditions of complete brine saturation were also lower than oil permeabilities measured at residual water saturation conditions. Whereas the end-point permeability and saturation data were useful and accurate, the unsteady-state results were not as good as expected. Apparently, gas trapped within the syringe pump that was used for several test measurements caused the brine injection rate to vary during "constant rate" tests. This effect was climinated, and tests on plug 4959B were repeated. Figure 9 shows unsteady-state oil/brine relative permeability results for plug 4959B. The test data are included in appendix $\mathrm{C}$. A second test with the plug and an additional test using plug 4961 provided similar results.

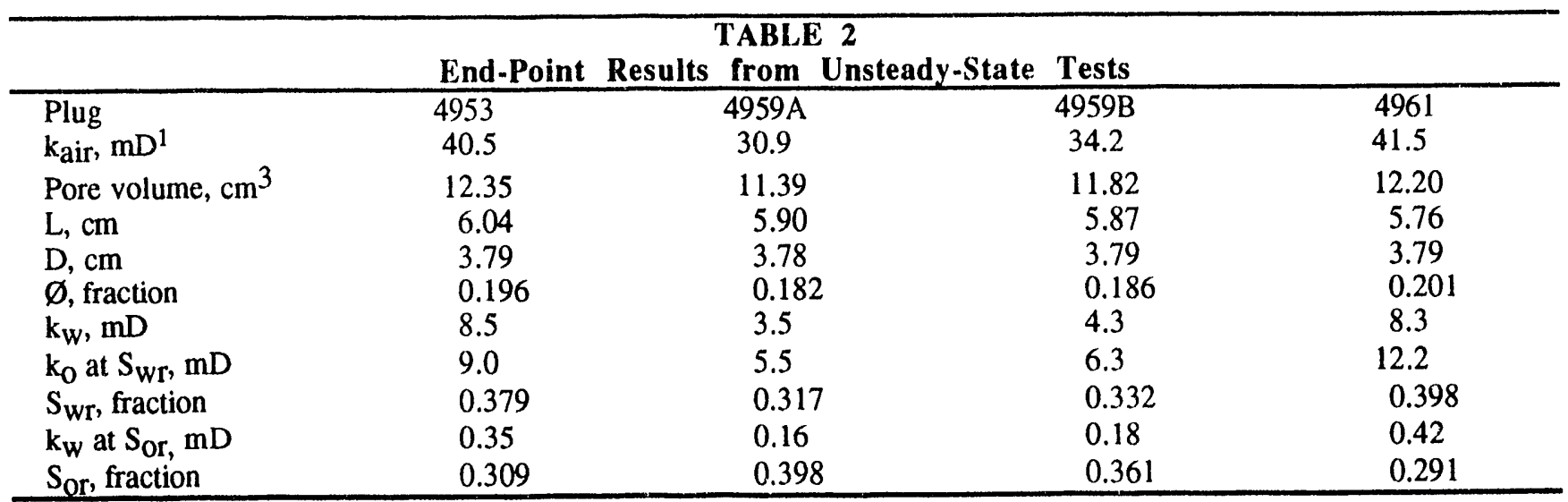

${ }^{1}$ Measured with 100 psig confining pressure 


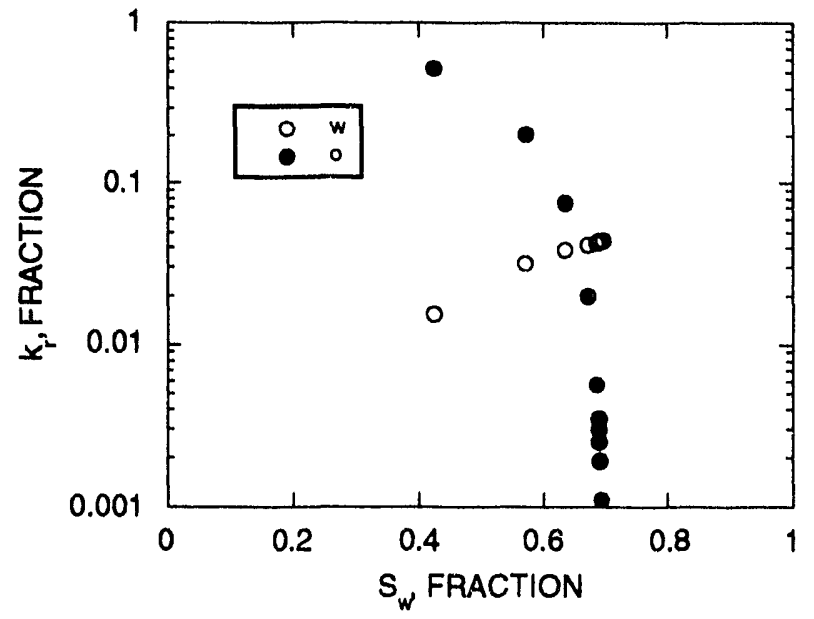

Fig. 9 Unsteady-state oll/brine relative permeablity results for plug 4959B.

\section{Steady-State Relative Permeability Tests}

\section{Sample Preparation}

A slab from the 4,959-ft depth interval was prepared for steady-state relative permeability tests. The rock was 8.3 $\mathrm{cm}$ long by $2 \mathrm{~cm}$ thick by $5.3 \mathrm{~cm}$ tall. The sample was oriented with bedding planes parallel to the long-axis. The $8.3 \mathrm{~cm}$ length was representative of the longest length thut can typically be cut from slabbed whole core. Figure 10 is a schematic of the sample. This sample shape was selected because microwave methods for measuring brine saturations work best when the microwaves pass through samples with rectangular cross sections. The end-pieces were fabricated from Lucite. Berea inserts were placed in the end-pieces. The purpose of the Berea sainustone inserts was to move capillary end-effects away from the sample and to mix fluids upstream from the rock. Kimwiper disposable wipers were placed between the Berea sandstone inserts and the sample. The slab was then jacketed with casting plastic. Microwave absorbants were placed above and below the sample to absorb microwaves which otherwise might bypass the sample. After attaching inlet and outlet flow and pressure tubing, the rock was inserted into a microwaveable coreholder. The system was pressure tested with a confining pressure of $1,000 \mathrm{psig}$ and was found to be leak tight.

\section{Permeability Measurements}

All steady-state measurements were conducted with 100 psig backpressure on the flow systen. $X$-ray and microwave scans were used to measure the saturation distributions within the sample during steady-state tests.

The gas permeability of the sample was measured as 3.0 $\mathrm{mD}$ with 100 psig backpressure on the flow system. Nitrogen gas was used as the gas phase for all steady-state gas tests. The rock was saturated with $2 \% \mathrm{KCl}$ brine, and the brine permeability was measured as $0.24 \mathrm{mD}$. The magnitude of the difference between the gas and brine permeabilities was too great, suggesting that the rock was not clean. Isopropyl alcohol and nitrogen gas were injected to clean and dry the rock. Some oil was removed from the rock by the alcohol even though the rock had been previously extracted with toluene and methanol for about 2 weeks. After cleaning the rock, the gas permeability was measured as $10.8 \mathrm{mD}$, and the brine permeability was found $5.8 \mathrm{mD}$. Inserting $10.8 \mathrm{mD}$ into Eq. 4 yields a water permeability prediction of $6.0 \mathrm{mD}$, which agrees well with the $5.8 \mathrm{mD}$ measured value.

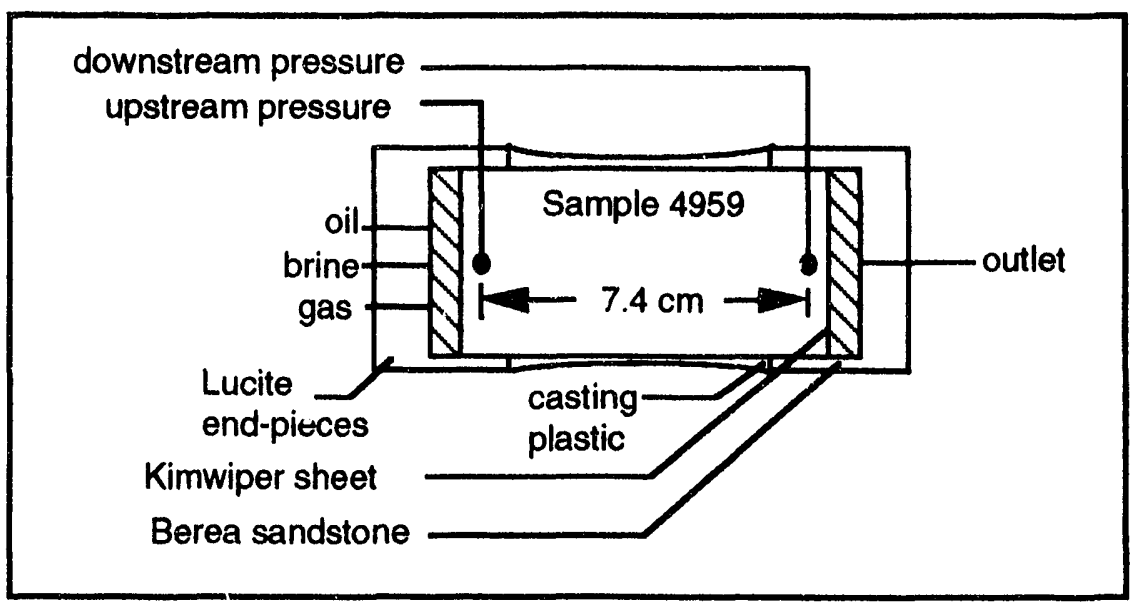

Fig. 10 Schematic of Sample 4959 when prepared for tests. 
The brine-saturated rock was flooded with hydrated nitrogen gas at $500 \mathrm{sccm}$ (standard cubic centimeters per minute) to establish residual water saturation conditions. The brine contained $5 \% \mathrm{KI}$ (potassium iodide) which served as an X-ray tag. After flooding for 5 days, the brine saturation was reduced to about $45 \%$. Additional flooding was conducted with dry gas in an effort to reduce the brine saturation by another 5 to $10 \%$. Permeability and saturation measurements were recorded for first-imbibition and second-drainage saturation cycles. Imbibition cycle results are shown in Fig. 11. Tables of all of the steadystate test data are included in appendix $C$.

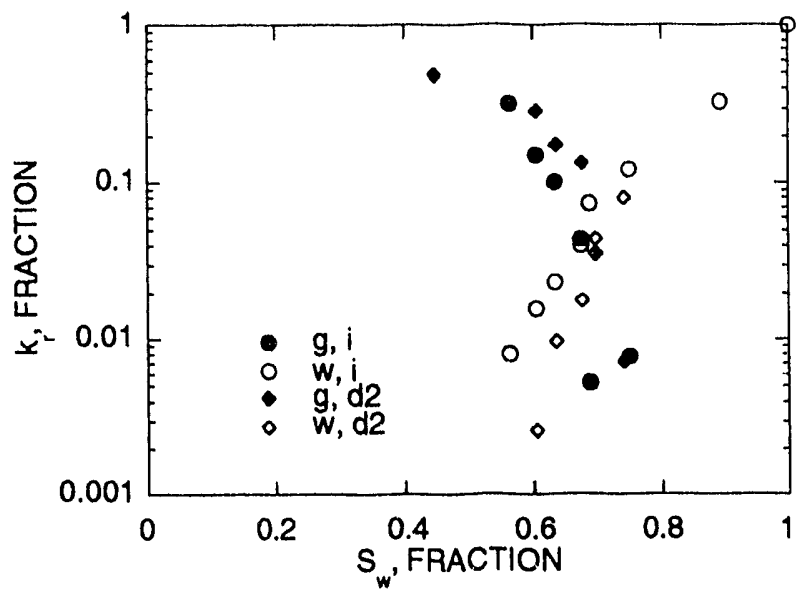

Fig. 11. Steady-state gas/water relative permeability results for plug 4959. Results are normalized with respect to $k_{W}=5.78 \mathrm{mD}$ at $S_{W}=$ 1.000 .

The rock was cleaned and was resaturated for oil/water relative permeability tests. A $2 \% \mathrm{KCl}$ brine was used for all subsequent tests. The oil phase consisted of Soltrol 100 tagged with iododecane to provide similar X-ray attenuation characteristics with the $2 \% \mathrm{KCl}, 5 \% \mathrm{KI}$ brine which was used in the previous test. This oil was used for all of the steady-state tests. The brine and oil viscosities were each nearly $1 \mathrm{cP}$.

Imbibition and second-drainage oil/water relative permeability tests and gas/oil tests with a residual water saturation present were conducted next. Oil/water results are shown in Fig. 12. The oil relative permeability results of Fig. 12 are in good agreement with those from the unsteady-state oil/brine test (Fig. 9), whereas the brine results do not match. The gas/oil test was conducted with a residual water saturation present within the rock. Gas relative permeability results from the gas/oil test are shown in Fig. 13. The gas relative permeability results from both gas/water and oil/water tests were very similar. The range of oil saturations which resulted during the gas/oil relative permeability test was narrow and close to the residual oil saturation condition.

The rock was flooded with brine to residual oil and gas saturation conditions. Brine and oil were injected into the rock with a brine frictional flow of 0.90 . Gas injection was initiated and three-phase relative permeability and saturation measurements were recorded as the gas rate was incrementally increased and both the oil and brine rates were decreased to maintain the ratio of brine to oil fractional flow. The rock was flooded with brine to return to residual oil and gas saturation conditions. Brine and oil were injected into the rock with a brine fractional flow of 0.6. Gas injection was initiated and three-phase measurements were recorded as the gas rate was increased and the brine and oil rates were decreased. Additional ineasurements were recorded for a final cycle which started with a brine fractional flow of 0.20 . Maximum injection rates were limited to prevent the pore pressure within the rock from exceeding $400 \mathrm{psig}$. The intent of this pressure limitation was to prevent excessive pressures from damaging the casting-plastic jacket which surrounded the rock and flow distribution end-pieces.

Three-phase results are shown in Figs. 14, 15, and 16 along with two-phase steady-state results for comparison. Three-phase brine relative permeability results are very similar to those from two-phase measurements. Gas and oil three-phase results are clustered near their two-phase residual saturation conditions. The three-phase gas and oil results are similar to those from the two-phase tests at comparable saturation conditions. Gas and oil saturations below their two-phase residual conditions were achieved during the three-phase tests.

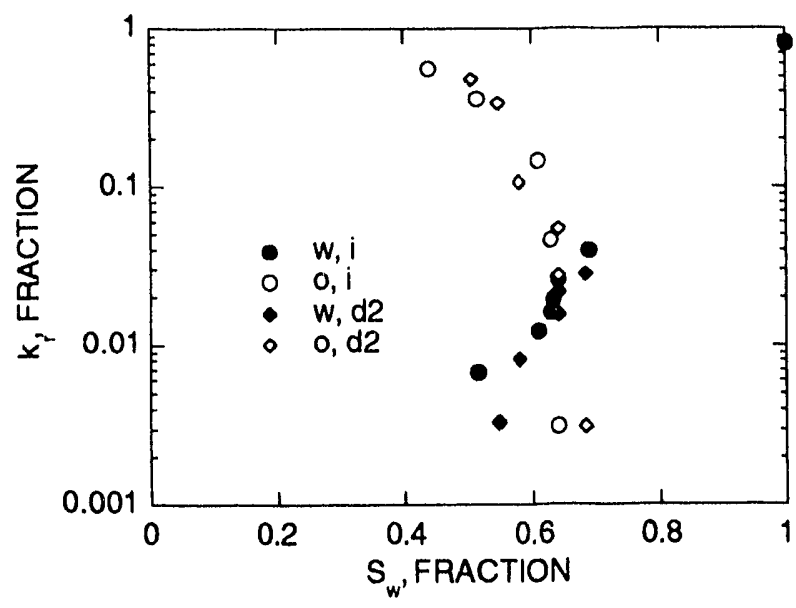

Fig. 12. Steady-state oilwater relative permeability results for plug 4959. Results are normalized with respect to $k_{w}=5.78 \mathrm{mD}$ at $S_{w}=$ 1.000 . 


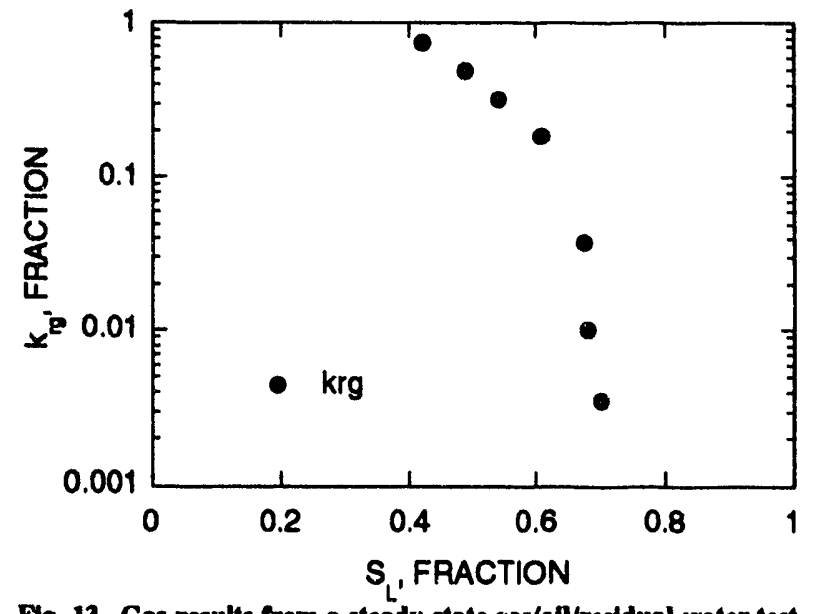

Fig. 13. Gas results from a steady-state $[\mathrm{as} / \mathrm{oll} / \mathrm{res}$ dual water test wth plug 4959. Results are normalized with respect to $\mathrm{K}_{\mathrm{W}}=\mathbf{5 . 7 8}$ $\mathrm{mD}$ at $\mathrm{S}_{\mathrm{w}}=1.000$.

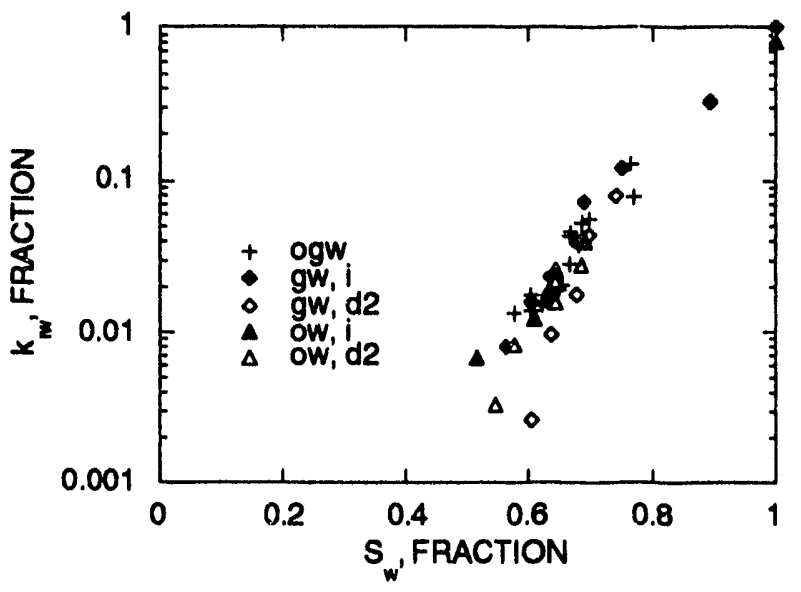

Fig. 14. Two- and three-phase brine steady-state relative permeablilty results for plug 4959. Results are normalized with respect to $k_{w}=5.78 \mathrm{mD}$ at $S_{w}=1.000$.

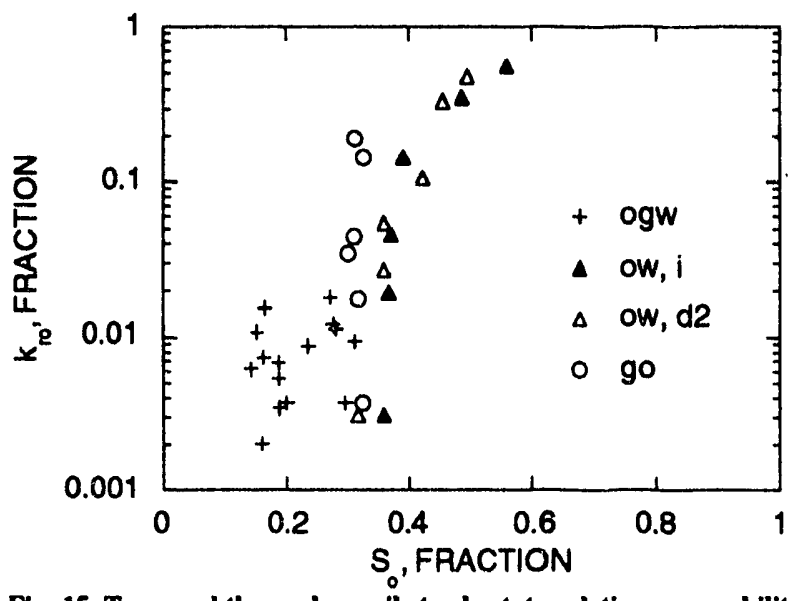

Fig. 15 Two- and three-phase oll steady-state relative permeability results for plug 4959 . Results are normalkzed with respect to $\mathrm{k}_{\mathrm{w}}=$ $5.78 \mathrm{mD}$ at $\mathrm{S}_{\mathrm{w}}=1.000$.

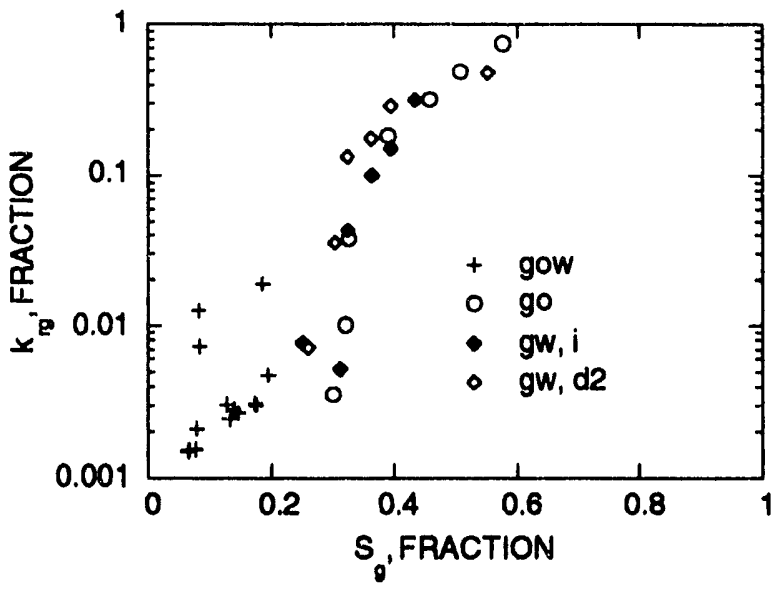

Fig. 16 Two- and three-phase gas steady-state relative permeability results for plug 4959. Results are normalized with respect to $k_{V}=$ $5.78 \mathrm{mD}$ at $S_{\mathrm{w}}=1.000$.

\section{Reservoir Condition Tests}

Reservoir condition tests were started at the end of the reporting period, but insufficient results were available for inclusion in this report. A capillary tube viscometer was assembled and calibrated to measure fluid viscosities during reservoir condition tests. A temperature bath was built to accomodate the pumps, coreholder, tubing, and fluid reservoirs while maintaining provisions for $\mathrm{X}$-ray and microwave scans. Methods for calibrating the $\mathrm{X}$-ray to fluid saturations during high-temperature tests were developed. These improvements in reservoir condition test methodologies and instruments are described in appendix D.

\section{Discussion}

Plans to form a consortium with petroleum industry participants were finalized during the first quarter of the project year, and a meeting with the participants was held during the middle of the second quarter. As a result, selection of the Almond formation rock for characterization during the project year was not finalized until early in the second quarter. The second half of the fourth quarter was spent analyzing results. As a result, most of the laboratory testing described in this report was conducted during a 7month period. Because of the short ir testing year and lower permeability sample, fewer three-phase relative permeability measurements were recorded than were originally envisioned.

Air-brine capillary pressure versus brine saturation results were in good agreement from centrifuge, mercury injection, and porous plate experiments. Insufficient centrifugal forces were developed using the centrifuges onhand to obtain full oil/brine capillary pressure versus brine saturation curves. For these low-permeability samples, the use of an ultracentrifuge for oil/brine centrifuge tests would have been more appropriate.

The prediction that fluid trapping would affect laboratory flow experiments with this rock appears to have been true 
in that residual brine saturations were high during relative permeability experiments. The range of relative permeability versus saturation data measured during the three-phase flow experiments was narrow. Fines migration and clay effects did not appear to be a problem in laboratory experiments.

The sample for steady-state relative permeability tests was cut from a section of reservoir core. The sample was prepared to test the rock with flow parallel to the bedding planes. This constraint yielded a sample which was much shorter than other samples that have been used for this project in the past. However, reasonably good two- and three-phase steady-state relative permeability results were obtained using the sample. The microwaveable coreholder and core preparation techniques worked well so that steadystate oil/water, gas/water, and gas/oil/water measurements were all conducted on the same sample.

Oil relative permeability results were in good agreement from both unsteady- and steady-state oil/water tests, whereas the brine results were not similar. The brine relative permeability versus saturation plots from the steady-state oil/water test showed a more pronounced change in relative permeability with changes in saturation compared to the unsteady-state result. The steady-state brine data projected to the $\mathrm{k}_{\mathrm{rW}}=1$ at $\mathrm{S}_{\mathrm{W}}=1$ end point, whereas the unsteady-state data appeared to have a $k_{r w}=$ 0.1 at $S_{W}=1$ end point. The unsteady-state water relative permeability data appear to be incorrect. Better agreement might have been achieved had the sample been longer or if other test conditions had been imposed.

Working with reservoir rock instead of quarried rock such as Berea increased the level of complexity involved in testing the rock, but not excessively. Limiting the maximum pore pressure within the rock to $400 \mathrm{psig}$ reduced the range of relative permeability results that could be obtained in a reasonable length of time using the available laboratory equipment. A higher-permeability sample would have provided better opportunities experimentally but the core analyst must work with the rock of interest rather than idealized samples.

When calculating saturations, microwave and X-ray results from end-point calibrations were not in perfect agreement. Special tests were performed to check that the $\mathrm{X}$-ray and microwave devices were working properly. A discussion of the verification tests is given in appendix $C$. Both instruments appeared to be working properly. Except for some of the end points, plots of X-ray versus microwave data (natural $\log$ of $\mathrm{X}$-ray intensity versus natural log of incident over emergent microwave power) were linear for two-phase oil/water and gas/water data. An analysis of the data revealed that some of the microwave signal bypassed the sample near the $100 \%$ dry and $100 \%$ saturated sample conditions. Corrections were made to the microwave calibrations to bring the $\mathrm{X}$-ray and microwave saturation calibrations into agreement.

The oil was vacuum filtered and was reused during the three-phase tests. Evaporation of light ends apparently caused the relative concentration of the $\mathrm{X}$-ray dope within the oil to increase during the third set of three-phase measurements. The change in iododecane concentration was not compatible with the X-ray calibrations, so the final set of three-phase data was unusable. Some additional room-temperature three-phase measurements will be recorded during FY93.

Comparing the results for this Almond formation sample from the $4,959 \mathrm{ft}$ depth to FY91 project results for 260 $\mathrm{mD}$ fired Berea ${ }^{7}$ yields the following observations:

1. With each sample, two- and three-phase $\mathrm{k}_{\mathrm{rw}}$ versus $S_{W}$ trends were similar. For equivalent saturations below $S_{W}=75 \%$, the water relative permeabilities for the Almond formation rock were somewhat lower than those of the Berea.

2. Comparing oil relative permeability results, those of the Almond formation rock were generally greater than those of the Berea at equivalent oil saturations for both two- and three-phase flow systems. The Almond formation rock oil relative permeability results showed more scatter than those of the Berea.

3. Two-phase gas results for the Almond formation rock were generally less than those of the Berea. Three-phase relative permeabilities for the Almond formation rock were generally greater than those of the Berea at equivalent gas saturations. Three-phase gas relative permeability versus gas saturation results for both samples were scattered.

\section{Conclusions}

Some conclusions from this work are as follows:

1. The samples tested were strongly water-wet. USBM wettability indices from centrifuge tests were close to 1 .

2. Air-brine capillary pressure versus saturation characteristics were measured for one of the Almond formation samples using a variety of techniques. Air-brine capillary pressure data from porous plate, mercury injection, and air/brine centrifuge tests were very similar.

3. Oil/brine centrifuge capillary pressure versus saturation results were nearly identical regardless of whether decane or Soltrol 100 was used as the oil phase.

4. Thin section evaluations indicated that for the Almond formation samples examined, microporosity comprises 38 to $60 \%$ of the rock porosity. Clay filaments crossed many pore throats. The microporosity and clay were predicted to trap fluids during flow tests.

5. Unsteady-state and steady-state oil relative permeability results from oil/brine tests were almost identical. However, brine relative permeability results from the same tests were significantly different. In general, brine relative permeability measurements from the steady-state tests were lower than those of the unsteady-state tests. This is believed to result from the shortness of the unsteady-state test plugs and from laboratory testing techniques.

6. Sample preparation and testing techniques that were developed for the steady-state testing program were successful. Three-phase measurements were conducted with the sample subjected to $1,000 \mathrm{psig}$ confining pressure.

7. Comparing relative permeability results for the Almond formation sample from the $4959 \mathrm{ft}$ depth to the 260-mD fired Berea results from FY91: 
a. With each sample, two- and three-phase $\mathrm{k}_{\mathrm{rw}}$ versus $S_{\mathrm{W}}$ trends were similar. For equivalent saturations below $S_{W}=75 \%$, the water relative permeabilities for the Almond formation rock were somewhat lower than those of the Berea.

b. Comparing oil relative permeability results, those of the Almond formation rock were generally greater than those of the Berea at equivalent oil saturations for both two- and three-phase fiow systems. The Almond formation rock oil relative permeability results showed more scatter than those of the Berea.

c. Two-phase gas results for the Almond formation rock were generally less than those of the Berea. Threephase reiative permeabilities for the Almond formation rock were generally greater than those of the Berea at equivalent gas saturations. Three-phase gas relative permeability versus gas saturation results for both samples were scattered.

\section{Technology Transfer}

A consortium was formed with two major petroleum companies. The purpose of the consortium was to spread project costs among participants and to benefit from having representatives from major petroleum companies assist in the planning and steering of the project. Discussions among the Consortium members and project staff gave the project staff a better appreciation of the types of information required by reservoir engineers and special core analysts for simulation and reservoir evaluation.

Dan Maloney and Alan Brinkmeyer attended the Sisters City Technical Seminar on April 6-7 which was held by Exxon Production Research Company, Esso Norge, and Rogaland Research in Houston, TX. The seminar covered various aspects of reservoir condition special core analysis tests. After the seminar, Maloney and Brinkmeyer visited a special core analysis laboratory of one of the major oil companies in Houston and discussed measurements and experimental design with the core analysts.

Maloney gave talks on reservoir condition core analysis measurements for a major oil company during their special core analysis workshop in April and to NIPER researchers and the AWU scholars who are working at NIPER in May.

Maloney and Brinkmeyer attended the SCA/SPWLA Joint Annual Technical Conference and Exhibition in Oklahoma City on June 15-17. NIPER had an exhibition booth at the SCA/SPWLA meeting. Many copies of topical reports for the BE9 project were given to SCA/SPWLA members who visited the NIPER booth during the meeting. Maloney attended several API subcommittee meetings on routine core analysis during the project year.

\section{Acknowledgments}

This work was performed for the U. S. Department of Energy (DOE) under Cooperative Agreement DE-FC22. 83FE60149. The wort. was also supported by Mobil Research and Development Corporation and Unocal Corporation. The authors thank Willis Waldorf, Ron Masias, Sam Swan, and Liviu Tomutsa, all of NIPER, for their assistance in the laboratory with steady-state relative permeability, centrifuge capillary pressure, and CT scan measurements. Appreciation is also extended to Rick Schatzinger, also of NIPER, for his geologic and petrographic analyses. Finally, we thank the NIPER management and persorinel who reviewed this manuscript, and Rhonda Patterson, the DOE Project Manager, for her support.

\section{References}

1. E. Pittman, Relationship of Porosity and Permeability to Various Parameters Derived from Mercury Injection-Capillary Pressure Curves for Sandstone. AAPG Bulletin, v. 76, No. 2 (Feb. 1972) pp. 191 - 198.

2. J. Thomeer, Introduction of a Pore Geometrical Factor Defined by the Capillary Pressure Curve, J. Pet. Tech. (March 1960) 73-77.

3. B. Swanson, A Simple Correlation Between Permeabilities and Mercury Capillary Pressures, J. Pet. Tech (December 1981) 2498-2504.

4. I. Juhasz, The Central Role of $Q v$ and Formation Water Salinity in the Evaluation of Shaly Formations, Paper AA pres. at the SPWLA 20th Annual Logging Symposium, Tulsa, (June 3-6, 1979).

5. V. Pugh, D. Thomas, and S. Gupta. Correlations of Liquid and Air Permeabilities for Use in Reservoir Engineering Studies, paper SCA 9012 pres. at the Society of Core Analysts Annual Tech. Conf., Dallas, (August 1416, 1990).

6. D. R. Maloney, A. D. Brinkmeyer, M. M. Honarpour, 1990. Relative Permeabilities and Other Characteristics of 700-Millidarcy Fired Berea Sandstone, DOE Report NIPER-496, pp 9-11.

7. D. R. Maloney, and A. D. Brinkmeyer, 1992. ThreePhase Relative Permeabilities and Other Characteristics of 260-mD Fired Berea, DOE Report NIPER-, pp 22-23. 


\section{APPENDIX A CONFINED PLUG PORE VOLUME MEASUREMENTS}

\section{Summary}

A method was desired to measure plug pore volume changes with changes in confining pressure. An apparatus was designed and constructed for this purpose. The measurement technique is based on gas expansion (Boyles/Charles laws). Calculations were patterned after those presented at one of the API Subcommittee on Routine Core Analysis meetings by one of the participating organizations. After calibrating the system, porosity reduction experiments were performed on three 1.5 inch-diameter perm plug samples with confining pressures in the range from 500 to 4,100 psig. The porosities of the test plugs (calculated from changes in pore volumes) were reduced by about 0.5 porosity percent units when the confining pressure was increased from 500 to 4,100 psig. Pore volumes measured at 500 psig with the apparatus we: \& similar to those calculated from tests on unconfined samples within a Boyles/Charles law porosimeter. Calibration procedures and test results are presented to provide guidance to others who may wish to construct a similar apparatus.

\section{Introduction}

A question that often arises when routine laboratory results are evaluated is "How well do these measurements reflect the rock properties under reservoir conditions?" This is especially critical when considering rock porosities since reservoir reserves are computed using porosity figures. A method to measure changes in pore volume with stress was required for our lab. The technique is similar to those used with routine gas porosimeters except that the sample is subjected to confining pressure. Test calculations yield pore volumes directly rather than a measure of the grain volume as provided by the routine porosimeter. Plug bulk volumes computed by adding pore volumes measured using the confined-plug gas expansion technique and grain volumes measured by routine gas porosimetry appear to be more accurate than bulk volumes calculated from micrometer measurements because the micrometer measurements do not always account for rounded sample end-face edges, chips, or small surface vugs.

\section{Experimental Procedures}

The apparatus consists of a reference volume and pressure transducer that are seperated from the inlet tubing to the confining core plug by a valve as shown in Fig. A-1. The apparatus was constructed using a Hoke $40 \mathrm{~cm}^{3}$ stainless steel cylinder as the major constituent of the reference volume, a Validyne pressure transducer and power supply/readout, several 3-way and 2-way ball valves, 2 needle valves, and 3 receptacles with known volumes for calibration purposes. The initial gas pressure within the reference vessel was zelected as $125.0 \mathrm{psig}$. A calibration vessel of known volume was connected to the reference vessel immediately downstream from the connecting valve. The pressure within the calibration vessel was initially 0 psig. The 3-way ball valve was turned allowing communication between the reference volume and the calibration vessel. After equilibration, the pressure was recorded. Copper spheres (BBs) with known volumes were used to alter the calibration vessel volume for subsequent measurements. Utilizing three different calibration vessels and the copper spheres, 50 calibration volume/expansion pressure data pairs were recorded. These results are included in Table A1 and Figs. A2 and A3. The fitting normally connected to either a calibration vessel or the coreholder was plugged, and the valve was opened to find the actual beginning pressure of the reference volume. The actual initial pressure for $0.0 \mathrm{~cm}^{3}$ calibration volume was found to be $124.8 \mathrm{psig}$. The fit to the calibration data shown in Fig. A3 is a polynomial equation. The correlation coefficient for the fit was better than 0.999 . This calibration equation was applied to data from subsequent core plug tests to determine pore volumes. Equation A1 can also be used to calculate the pore volume if the reference cell volume and system dead volumes are known.

$$
V_{p}=V_{r} \frac{\left(\frac{P_{1} Z_{2}}{P_{2} Z_{1}}-1\right)-V_{v}}{\left(1-\frac{P_{a} Z_{2}}{P_{2} Z_{a}}\right)}-V_{d}
$$

where

$P_{a}=$ absolute atmospheric pressure initially in the sample

$\mathrm{P}_{1}$ = absolute internal reference volume pressure initially, 125 psia

$P_{2}=$ absolute expanded pressure, $p$ sia

$\mathrm{Z}_{1}$ = gas compressibility factor at $\mathrm{P}_{1}$ and $\mathrm{T}_{1}$

$Z_{2}=$ gas compressibility factor at $P_{2}$ and $T_{2}$

$\mathrm{Z}_{\mathrm{a}}$ = gas compressibility factor at $\mathrm{P}_{\mathrm{a}}$ and $\mathrm{T}_{1}$

$\mathrm{V}_{\mathrm{r}}=$ reference chamber volume

$\mathrm{V}_{\mathrm{d}}=$ system dead volume

$\mathrm{V}_{\mathrm{v}}$ = valve displacement volume (from closed to open position)

The data from Table 1 were used to construct a plot of

$$
\left(V_{p}+V_{d}\right)\left(1-\frac{P_{a} Z_{2}}{P_{2} Z_{a}}\right) \text { versus }\left(\frac{P_{1} Z_{2}}{P_{2} Z_{1}}-1\right)
$$


The data can be fit with a straight line in which the slope of the line is $\mathrm{V}_{\mathrm{r}}$ and the intercept is $\mathrm{V}_{\mathrm{v}}$. Figure $\mathrm{A} 4$ shows the plotted data. From the best fit to the data, the reference chamber volume is $46.38 \mathrm{~cm}^{3}$ and the valve displacement volume is $0.138 \mathrm{~cm}^{3}$.

Once the calibration curve was established, the empty coreholder was connected to the porosimeter, and the dead volume of the holder was determined. After these pressures and volumes were documented, rock samples were tested.

Three samples of reservoir rock from the Arch Unit of the Almond formation were then selected. These samples ranged from 3.78 to $3.79 \mathrm{~cm}$ in diameter and 5.76 to 5.90 $\mathrm{cm}$ in length. Each sample was allowed to stabilize with a confining pressure of 500 psig before pore volume measurements were recorded. Additional measurements were recorded as the confining pressure was increased in $500 \mathrm{psig}$ increments to $4,000 \mathrm{psig}$. Increases in pore pressure were recorded with corresponding confining pressures. After the maximum overburden pressure stabilized and the pore pressure was recorded, the overburden pressure was reduced to the initial level of 500 psig to compare the final pore pressure with the initial pore pressure value.

The grain volumes and bulk volumes of the samples were also measured using the conventional gas-expansion method and micrometer measurements for comparison purposes.

\section{Results and Discussion}

Sample porosities with 500 psig confining pressure were lower than those of the samples when tested unconfined. Porosities at 500 psig were from 0.08 to 0.22 porosity percentage units lower than measurements with unconfined samples. Micrometer measurements of sample bulk volumes do not account for rounded sample corners, chips, or large surface vugs, so pore volumes interpreted from routine gas porosimetry tests with unconfined samples are sometimes overestimated. These rounded corners do not affect the pore volume measurement to such an extent for measurements on confined samples because the core sleeve conforms to the sample and intrudes into the gaps and vugs. Since the conventional method measures the grain volume directly, bulk volumes must be measured very accurately with the conventional method or pore volume results wil! be in error. Accurate bulk volumes can be obtained by mercury immersion. However, the mercury can contaminate the sample. The technique described in this report, which is utilized by other labs as well, provides a means for accurate pore volume measurements. Pore volumes by this method plus grain volumes from conventional analysis can be combined to yield sample bulk volumes. The porosities calculated from conventional measurements are shown along with those from tests on the confined samples in Figs. A5 through A7.

Errors associated with the confined plug measurements can be minimized in most cases by careful attention to detail when the sample is mounted in the coreholder. There is one problem inherent in this system, however. The sleeve will be forced into surface pores of the sample when the overburden pressure is applied. Depending on the lithology of the sample this ccidld be a significant problem. Samples with exposed vugs will suffer the mnst porosity reduction because of this sleeve intrusion. With most samples, however, this seems to cause minimal porosity reduction. Attention should also be given to insuring that the sleeve actually conforms to the sample during the test.

\section{Conclusions and Recommendations}

Data obtained using this method followed trends one would normally expect, and no evidence was observed that would invalidate this procedure. There are some improvements, however, which would enhance the effectiveness of this apparatus. Most significant of these would be a more accurate means to measure the confining pressure. The confining pressure gauge now being employed is only accurate to $\pm 50 \mathrm{psi}$. Other improvements to the system now envisioned would increase the ease of operation only.

This system should not be considered as a replacement for methods now employed; however, information obtained in this way may help models more accurately predict reservoir performance. 
TABLE A1

Calibration Data

\begin{tabular}{cccccc}
\hline $\begin{array}{c}\text { Known volume } \\
\mathbf{c m}^{\mathbf{3}}\end{array}$ & $\begin{array}{c}\text { Pressure } \\
\text { psig }\end{array}$ & $\begin{array}{c}\text { Known } \\
\mathbf{c m}^{\mathbf{3}}\end{array}$ & $\begin{array}{c}\text { volume } \\
\text { p sig }\end{array}$ & $\begin{array}{c}\text { Known } \\
\mathbf{c m}^{\mathbf{3}}\end{array}$ & $\begin{array}{c}\text { volume } \\
\text { Ps ig }\end{array}$ \\
\hline 22.23 & 84.2 & 15.06 & 94.3 & 8.72 & 105.0 \\
21.80 & 84.7 & 14.62 & 95.0 & 8.50 & 105.4 \\
21.36 & 85.2 & 14.19 & 95.7 & 8.29 & 105.8 \\
20.93 & 85.8 & 13.75 & 96.4 & 7.85 & 106.6 \\
20.49 & 86.4 & 13.32 & 97.1 & 7.42 & 107.5 \\
20.06 & 87.0 & 12.88 & 97.8 & 6.98 & 108.4 \\
19.62 & 87.7 & 12.45 & 98.5 & 6.55 & 109.3 \\
19.19 & 88.2 & 12.02 & 99.2 & 6.11 & 110.2 \\
18.75 & 88.8 & 11.58 & 99.9 & 5.68 & 111.1 \\
18.32 & 89.4 & 10.46 & 101.7 & 2.48 & 118.0 \\
17.88 & 89.9 & 10.24 & 102.1 & 2.26 & 118.6 \\
17.45 & 90.5 & 10.03 & 102.6 & 2.05 & 119.1 \\
17.23 & 91.1 & 9.81 & 103.0 & 1.83 & 119.7 \\
16.80 & 91.7 & 9.59 & 103.3 & 1.61 & 120.2 \\
16.36 & 92.4 & 9.37 & 103.7 & 1.39 & 120.8 \\
15.93 & 93.0 & 9.16 & 104.2 & 1.18 & 121.3 \\
15.49 & 93.6 & 8.94 & 104.6 & 0.00 & 124.8 \\
\hline
\end{tabular}

TABLE A2

Porosity (\%) Versus Confining Pressure Results

\begin{tabular}{cccc}
\hline $\begin{array}{c}\text { Plug } \\
\text { C. Pressure, psig }\end{array}$ & 4959A & 4949 B & 4961 \\
\hline 500 & 18.93 & 19.23 & 19.99 \\
700 & 18.85 & 19.15 & 19.92 \\
850 & 18.78 & & 19.84 \\
900 & & & 19.76 \\
1,050 & 18.69 & 19.07 & \\
1,100 & & & 19.68 \\
1,250 & 18.62 & & \\
1,300 & & 18.99 & 19.60 \\
1,350 & 18.53 & & \\
1,600 & & 18.92 & 19.52 \\
1,650 & 18.46 & & \\
1,750 & 18.38 & & 19.43 \\
1,950 & & 18.83 & 19.36 \\
2,150 & 18.30 & & \\
2,250 & & 18.76 & 0.63 \\
2,350 & & & \\
2,650 & & 0.47 & \\
2,700 & & & \\
2,750 & 0.63 & & \\
3,100 & & & \\
3,500 & & & \\
\hline Total change & & & \\
over measured & range & & \\
\hline
\end{tabular}


TABLE A3



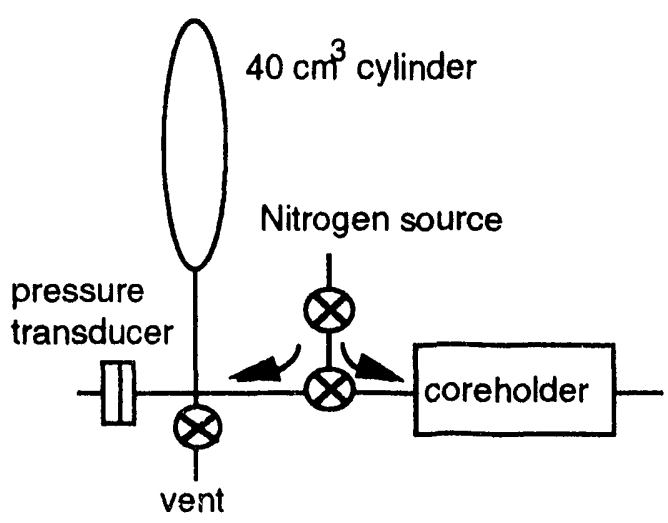

Fig. A1 Simplified schematic of the apparatus.

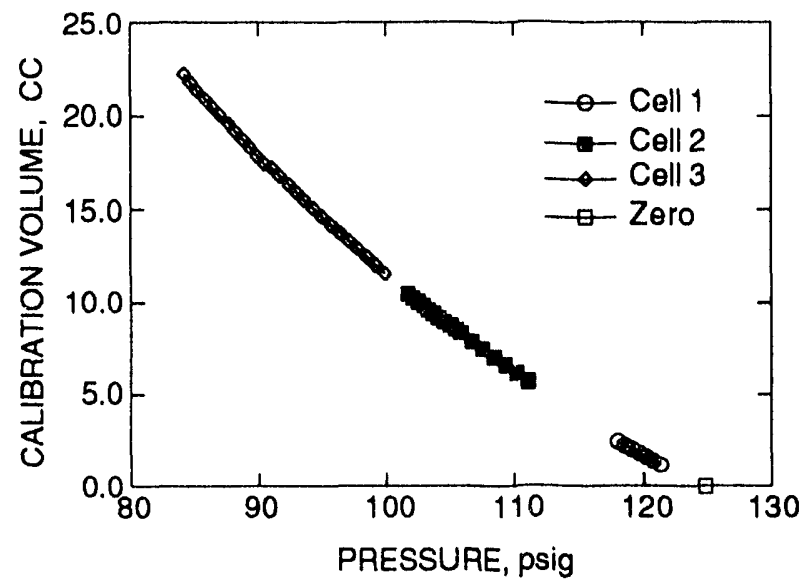

Fig. A2 Volume versus pressure measurements during calibration steps.

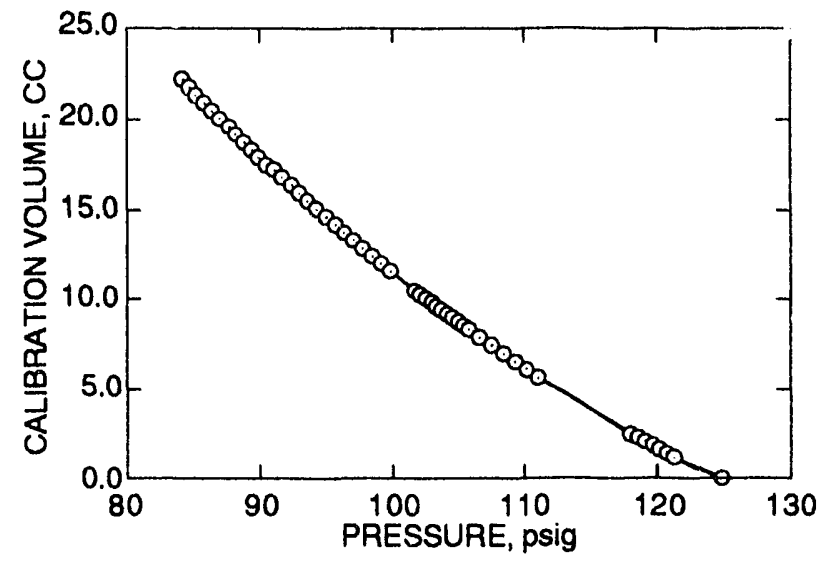

Fig. A3 Calibration curve developed using the data of Fig. 2.

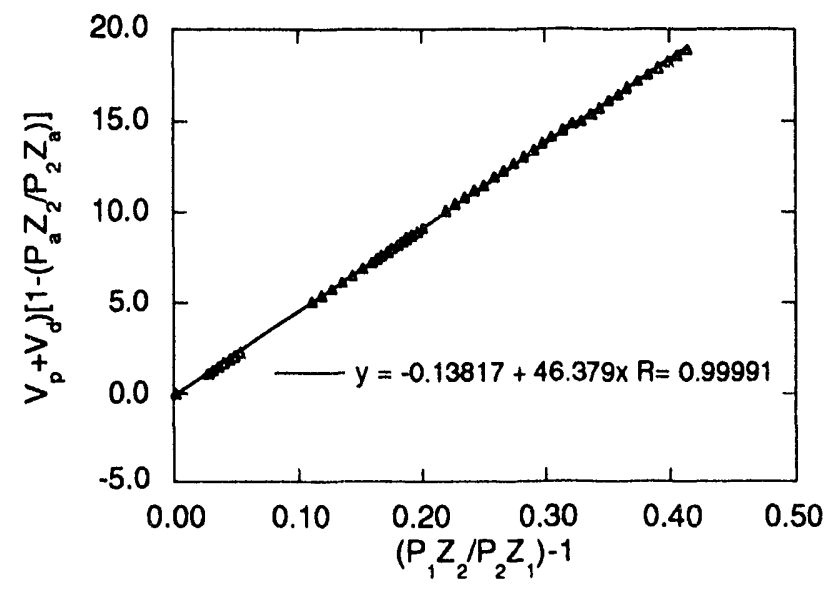

Fig. A4 Plot for determining the valve dead volume and reference chamber volume. 


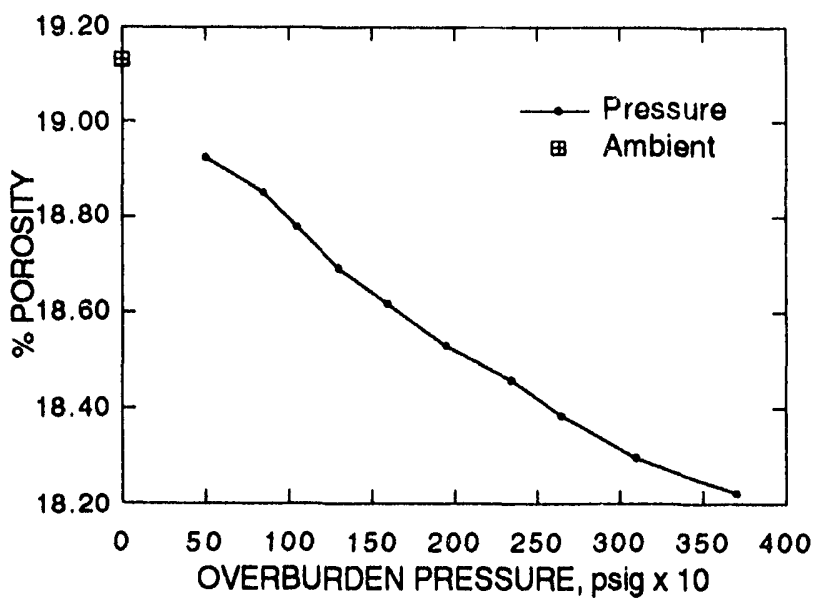

Fig. A5 Change in porosity with stress for plug 4959A.

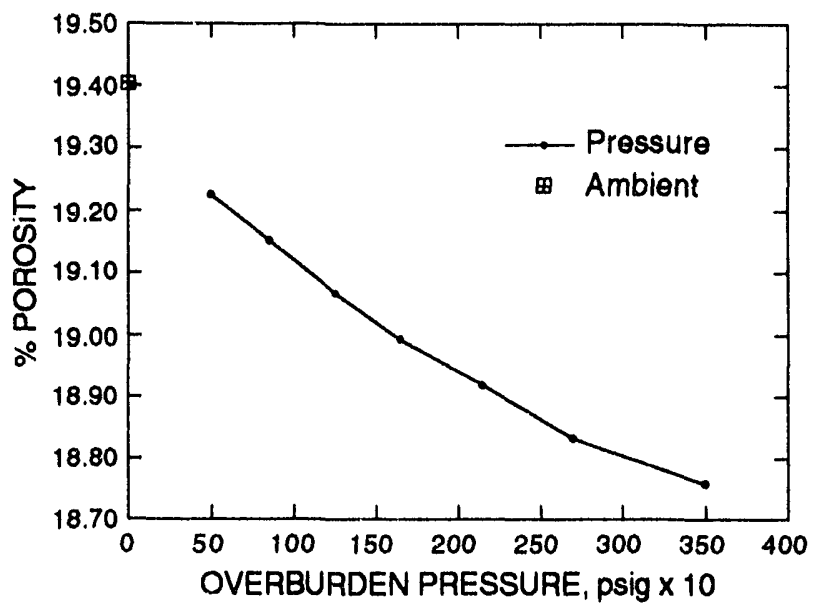

Fig. A6 Change in porosity with stress for plug 4959B.



Fig. A7 Change in porosity with stress for plug 4961. 


\title{
APPENDIX B \\ CAPILLARY PRESSURE AND WETTABILITY DATA AND MEASUREMENT METHODS
}

\author{
Mercury Intrusion Porosimetry
}

Sample 4953

Total intrusion volume:

Sample wt:

Porosity:

$0.0915 \mathrm{~mL} / \mathrm{g}$

$28.4518 \mathrm{~g}$

$19.67 \%$

Bulk density:

$2.15 \mathrm{~g} / \mathrm{mL}$

Median pore diameter:

Median pore diameter (area):

Average pore diameter (4V/A):

Apparent (skeletal) density:
1.48 vol $\mu \mathrm{m}$

$0.0064 \mu \mathrm{m}$

$0.0626 \mu \mathrm{m}$

$2.676 \mathrm{~g} / \mathrm{mL}$

The sample was evacuated to $50 \mu \mathrm{m} \mathrm{Hg}$ for 5 minutes before starting mercury injection. $\mathrm{V}^{\text {in }}$ is the cumulative volume of mercury injected.

TABLE B1

Plug 4953 mercury intrusion test results

\begin{tabular}{|c|c|c|c|c|c|c|c|c|c|}
\hline $\begin{array}{l}\text { Pc, } \\
\text { psi }\end{array}$ & $\begin{array}{r}\mathrm{d}, \\
\mu \mathrm{m}\end{array}$ & $\begin{array}{l}\text { Vin, } \\
\mathrm{mL} / \mathrm{g}\end{array}$ & $\begin{array}{l}\text { Hg sat, } \\
\% \text { BV }\end{array}$ & $\begin{array}{l}\text { Hg sat. } \\
\text { PV frac }\end{array}$ & $\begin{array}{l}P_{c}, \\
\text { psi }\end{array}$ & $\begin{array}{l}d, \\
\mu \mathrm{m}\end{array}$ & $\begin{array}{l}V_{\text {in }}, \\
\mathrm{mL/g}\end{array}$ & $\begin{array}{l}\text { Hg sat. } \\
\% \text { BV }\end{array}$ & $\begin{array}{l}\text { Hg sat. } \\
\text { PV frac } \\
\end{array}$ \\
\hline 0.5 & $3.50 \mathrm{E}+02$ & $0.00 \mathrm{E}+00$ & 0.00 & 0.000 & 11949.1 & $1.51 \mathrm{E}-02$ & $8.51 \mathrm{E}-02$ & 18.29 & 0.930 \\
\hline 1.0 & $1.75 E+02$ & $2.40 \mathrm{E}-03$ & 0.52 & 0.026 & 12560.2 & $1.44 \mathrm{E}-02$ & $8.54 \mathrm{E}-02$ & 18.36 & 0.933 \\
\hline 1.5 & $1.18 E+02$ & $3.40 \mathrm{E}-03$ & 0.73 & 0.037 & 13055.7 & 1.39E-02 & $8.55 \mathrm{E}-02$ & 18.38 & 0.934 \\
\hline 2.1 & $8.83 E+01$ & $3.70 \mathrm{E}-0.3$ & 0.80 & 0.040 & 13607.1 & $1.33 \mathrm{E}-02$ & $8.57 \mathrm{E}-02$ & 18.42 & 0.937 \\
\hline 3.0 & $5.99 \mathrm{E}+01$ & $3.90 \mathrm{E}-03$ & 0.84 & 0.043 & 13938.7 & $1.30 \mathrm{E}-02$ & 8.58E-02 & 18.44 & 0.938 \\
\hline 4.0 & $4.52 E+01$ & $4.00 \mathrm{E}-03$ & 0.86 & 0.044 & 14299.2 & $1.26 \mathrm{E}-02$ & 8.59E-02 & 18.47 & 0.939 \\
\hline 5.5 & $3.29 E+01$ & 4.10E-03 & 0.88 & 0.045 & 14542.1 & $1.24 \mathrm{E}-02$ & $8.60 \mathrm{E}-02$ & 18.49 & 0.940 \\
\hline 7.0 & $2.59 E+01$ & $4.20 \mathrm{E}-03$ & 0.90 & 0.046 & 14937.3 & $1.21 \mathrm{E}-02$ & $8.61 \mathrm{E}-02$ & 18.51 & 0.941 \\
\hline 8.5 & $2.14 E+01$ & 4.20E-03 & 0.90 & 0.046 & 15400.0 & $1.17 \mathrm{E}-02$ & $8.62 \mathrm{E}-02$ & 18.53 & 0.942 \\
\hline 10.5 & $1.73 E+01$ & $4.30 \mathrm{E}-03$ & 0.92 & 0.047 & 15741.2 & $1.15 \mathrm{E}-02$ & $8.63 \mathrm{E}-02$ & 18.55 & 0.943 \\
\hline 12.9 & $1.40 \mathrm{E}+01$ & $4.40 \mathrm{E}-03$ & 0.95 & 0.048 & 16142.2 & $1.12 \mathrm{E}-02$ & $8.64 \mathrm{E}-02$ & 18.57 & 0.944 \\
\hline 15.9 & $1.14 \mathrm{E}+01$ & $4.60 \mathrm{E}-03$ & 0.99 & 0.050 & 16604.9 & $1.09 \mathrm{E}-02$ & $8.65 \mathrm{E}-02$ & 18.59 & 0.945 \\
\hline 20.0 & $9.05 E+00$ & $5.40 \mathrm{E}-03$ & 1.16 & 0.059 & | 16973.1 & $1.07 \mathrm{E}-02$ & $8.66 \mathrm{E}-02$ & 18.62 & 0.946 \\
\hline 23.0 & $7.87 E+00$ & $6.70 \mathrm{E}-03$ & 1.44 & 0.073 & 17329.8 & $1.04 \mathrm{E}-02$ & $8.66 \mathrm{E}-02$ & 18.62 & 0.946 \\
\hline 24.9 & $7.26 \mathrm{E}+00$ & $7.30 \mathrm{E}-03$ & 1.57 & 0.080 & 17692.3 & $1.02 \mathrm{E}-02$ & 8.67E-02 & 18.64 & 0.948 \\
\hline 29.9 & $6.05 E+00$ & $1.23 \mathrm{E}-02$ & 2.64 & 0.134 & 18072.0 & $1.00 \mathrm{E}-02$ & $8.68 \mathrm{E}-02$ & 18.66 & 0.949 \\
\hline 39.9 & $4.53 E+00$ & $2.36 \mathrm{E}-02$ & 5.07 & 0.258 & 18424.8 & $9.80 \mathrm{E}-03$ & $8.69 \mathrm{E}-02$ & 18.68 & 0.950 \\
\hline 50.0 & $3.62 \mathrm{E}+00$ & $2.95 \mathrm{E}-02$ & 6.34 & 0.322 & 18769.9 & $9.60 \mathrm{E}-03$ & $8.69 \mathrm{E}-02$ & 18.68 & 0.950 \\
\hline 59.7 & $3.03 E+00$ & 3.33E-02 & 7.16 & 0.364 & 19161.3 & $9.40 \mathrm{E}-03$ & $8.70 \mathrm{E}-02$ & 18.70 & 0.951 \\
\hline 74.6 & $2.42 E+00$ & $3.76 \mathrm{E}-02$ & 8.08 & 0.411 & 19732.0 & $9.20 \mathrm{E}-03$ & $8.71 \mathrm{E}-02$ & 18.72 & 0.952 \\
\hline 89.7 & $2.02 E+00$ & $4.07 \mathrm{E}-02$ & 8.75 & 0.445 & 20264.1 & $8.90 \mathrm{E}-03$ & 8.72E-02 & 18.74 & 0.953 \\
\hline 114.4 & $1.58 \mathrm{E}+00$ & 4.46E-02 & 9.59 & 0.487 & 20732.5 & $8.70 \mathrm{E}-03$ & $8.73 \mathrm{E}-02$ & 18.77 & 0.954 \\
\hline 139.6 & $1.30 E+00$ & $4.78 \mathrm{E}-02$ & 10.28 & 0.522 & 21162.5 & $8.50 \mathrm{E}-03$ & 8.74E-02 & 18.79 & 0.955 \\
\hline 174.2 & $1.04 E+00$ & $5.09 \mathrm{E}-02$ & 10.94 & 0.556 & 21596.2 & $8.40 \mathrm{E}-03$ & $8.74 \mathrm{E}-02$ & 18.79 & 0.955 \\
\hline 219.6 & $8.24 \mathrm{E}-01$ & $5.41 \mathrm{E}-02$ & 11.63 & 0.591 & 22003.0 & $8.20 \mathrm{E}-03$ & $8.75 \mathrm{E}-02$ & 18.81 & 0.956 \\
\hline 269.2 & $6.72 \mathrm{E}-01$ & $5.67 \mathrm{E}-02$ & 12.19 & 0.620 & 22564.0 & $8.00 \mathrm{E}-03$ & $8.76 \mathrm{E}-02$ & 18.83 & 0.957 \\
\hline 328.4 & $5.51 \mathrm{E}-01$ & $5.89 \mathrm{E}-02$ & 12.66 & 0.644 & 23144.3 & $7.80 \mathrm{E}-03$ & 8.77E-02 & 18.85 & 0.958 \\
\hline 418.2 & 4.33E-01 & $6.15 \mathrm{E}-02$ & 13.22 & 0.672 & 23688.0 & $7.60 \mathrm{E}-03$ & 8.77E-02 & 18.85 & 0.958 \\
\hline 519.9 & $3.48 \mathrm{E}-01$ & $6.36 \mathrm{E}-02$ & 13.67 & 0.695 & 24046.6 & $7.50 \mathrm{E}-03$ & $8.78 \mathrm{E}-02$ & 18.87 & 0.960 \\
\hline 638.2 & $2.83 \mathrm{E}-01$ & $6.54 \mathrm{E}-02$ & 14.06 & 0.715 & 24561.3 & 7.40E-03 & $8.79 \mathrm{E}-02$ & 18.90 & 0.961 \\
\hline 700.2 & $2.58 \mathrm{E}-01$ & $6.63 \mathrm{E}-02$ & 14.25 & 0.725 & 24966.2 & $7.20 \mathrm{E}-03$ & 8.80E-02 & 18.92 & 0.962 \\
\hline 798.3 & $2.27 \mathrm{E}-01$ & $6.73 \mathrm{E}-02$ & 14.47 & 0.736 & 25388.4 & $7.10 \mathrm{E}-03$ & 8.80E-02 & 18.92 & 0.962 \\
\hline 985.1 & $1.84 \mathrm{E}-01$ & $6.90 \mathrm{E}-02$ & 14.83 & 0.754 & 25808.7 & $7.00 \mathrm{E}-03$ & $8.81 \mathrm{E}-02$ & 18.94 & 0.963 \\
\hline 1198.3 & $1.51 \mathrm{E}-01$ & $7.07 \mathrm{E}-02$ & 15.20 & 0.773 & 26377.4 & $6.90 \mathrm{E}-03$ & $8.82 \mathrm{E}-02$ & 18.96 & 0.964 \\
\hline 1293.8 & $1.40 \mathrm{E}-01$ & $7.11 \mathrm{E}-02$ & 15.28 & 0.777 & 26844.0 & $6.70 \mathrm{E}-03$ & 8.82E-02 & 18.96 & 0.964 \\
\hline 1394.1 & $1.30 \mathrm{E}-01$ & $7.17 \mathrm{E}-02$ & 15.41 & 0.784 & 27320.1 & $6.60 \mathrm{E}-03$ & 8.83E-02 & 18.98 & 0.965 \\
\hline
\end{tabular}


TABLE B1 Continued

Plug 4953 mercury intrusion test results

\begin{tabular}{|c|c|c|c|c|c|c|c|c|c|}
\hline $\begin{array}{l}\text { Pc, } \\
\text { psi }\end{array}$ & $\begin{array}{r}\mathbf{d}, \\
\mu \mathbf{m}\end{array}$ & $\begin{array}{l}\mathrm{Vin}, \\
\mathrm{mL} / \mathrm{g} \\
\end{array}$ & $\begin{array}{l}\mathrm{Hg} \text { sat, } \\
\% \text { BV }\end{array}$ & $\begin{array}{l}\text { Hg sat. } \\
\text { PV frac }\end{array}$ & $\begin{array}{r}\text { Pc, } \\
\text { psi }\end{array}$ & $\begin{array}{l}\mathrm{d}, \\
\mu \mathrm{m}\end{array}$ & $\begin{array}{l}\text { Vin, } \\
\mathrm{mL} / \mathrm{g}\end{array}$ & $\begin{array}{l}\text { Hg sat } \\
\% \text { BV } \\
\end{array}$ & $\begin{array}{l}\text { Hg sat. } \\
\text { PV frac } \\
\end{array}$ \\
\hline 1498.6 & $1.21 \mathrm{E}-01$ & $7.24 \mathrm{E}-02$ & 15.56 & 0.791 & 27717.3 & $6.50 \mathrm{E}-03$ & $8.84 \mathrm{E}-02$ & 19.00 & 0.966 \\
\hline 1598.2 & $1.13 \mathrm{E}-01$ & $7.29 \mathrm{E}-02$ & 15.67 & 0.797 & 28162.6 & $6.40 \mathrm{E}-03$ & $8.84 \mathrm{E}-02$ & 19.00 & 0.966 \\
\hline 1692.2 & 1.07E-01 & 7.33E-02 & 15.76 & 0.801 & 28889.4 & $6.30 \mathrm{E}-03$ & $8.85 \mathrm{E}-02$ & 19.02 & 0.967 \\
\hline 1893.5 & $9.55 \mathrm{E}-02$ & $7.43 \mathrm{E}-02$ & 15.97 & 0.812 & 29396.5 & $6.20 \mathrm{E}-03$ & $8.86 \mathrm{E}-02$ & 19.05 & 0.968 \\
\hline 2046.9 & 8.84E-02 & 7.48E-02 & 16.08 & 0.817 & 29872.7 & $6.10 \mathrm{E}-03$ & $8.87 \mathrm{E}-02$ & 19.07 & 0.969 \\
\hline 2191.1 & $8.25 \mathrm{E}-02$ & $7.53 \mathrm{E}-02$ & 16.19 & 0.823 & 30412.5 & $6.00 \mathrm{E}-03$ & $8.87 \mathrm{E}-02$ & 19.07 & 0.969 \\
\hline 2343.8 & 7.72E-02 & 7.57E-02 & 16.27 & 0.827 & 30867.5 & $5.90 \mathrm{E}-03$ & $8.87 \mathrm{E}-02$ & 19.07 & 0.969 \\
\hline 2489.5 & $7.27 \mathrm{E}-02$ & $7.62 \mathrm{E}-02$ & 16.38 & 0.833 & 31256.9 & $5.80 \mathrm{E}-03$ & $8.88 \mathrm{E}-02$ & 19.09 & 0.970 \\
\hline 2638.2 & $6.86 \mathrm{E}-02$ & $7.66 \mathrm{E}-02$ & 16.47 & 0.837 & 31762.0 & $5.70 \mathrm{E}-03$ & 8.89E-02 & 19.11 & 0.972 \\
\hline 2692.0 & $6.72 \mathrm{E}-02$ & $7.69 \mathrm{E}-02$ & 16.53 & 0.840 & 32301.8 & $5.60 \mathrm{E}-03$ & $8.89 \mathrm{E}-02$ & 19.11 & 0.972 \\
\hline 2836.0 & $6.38 \mathrm{E}-02$ & 7.72E-02 & 16.60 & 0.844 & 32857.0 & $5.50 \mathrm{E}-03$ & 8.90E-02 & 19.13 & 0.973 \\
\hline 2990.4 & $6.05 \mathrm{E}-02$ & $7.77 \mathrm{E}-02$ & 16.70 & 0.849 & 33487.5 & $5.40 \mathrm{E}-03$ & 8.91E-02 & 19.15 & 0.974 \\
\hline 3235.8 & $5.59 \mathrm{E}-02$ & $7.82 \mathrm{E}-02$ & 16.81 & 0.855 & 33992.6 & $5.30 \mathrm{E}-03$ & $8.92 \mathrm{E}-02$ & 19.17 & 0.975 \\
\hline 3487.0 & $5.19 \mathrm{E}-02$ & $7.87 \mathrm{E}-02$ & 16.92 & 0.860 & 34632.6 & $5.20 \mathrm{E}-03$ & $8.92 \mathrm{E}-02$ & 19.17 & 0.975 \\
\hline 3732.5 & 4.35E-02 & $7.91 \mathrm{E}-02$ & 17.00 & 0.864 & 35448.1 & $5.10 \mathrm{E}-03$ & 8.93E-02 & 19.20 & 0.976 \\
\hline 3990.8 & $4.53 \mathrm{E}-02$ & $7.97 \mathrm{E}-02$ & 17.13 & 0.871 & 36198.1 & $5.00 \mathrm{E}-03$ & $8.94 \mathrm{E}-02$ & 19.22 & 0.977 \\
\hline 4232.0 & $4.27 \mathrm{E}-02$ & $8.00 \mathrm{E}-02$ & 17.20 & 0.874 & 36936.5 & $4.90 \mathrm{E}-03$ & $8.95 \mathrm{E}-02$ & 19.24 & 0.978 \\
\hline 4480.5 & $4.04 \mathrm{E}-02$ & $8.03 E-02$ & 17.26 & 0.878 & 37597.7 & 4.80E-03 & $8.95 \mathrm{E}-02$ & 19.24 & 0.978 \\
\hline 4725.5 & $3.83 \mathrm{E}-02$ & 8.06E-02 & 17.33 & 0.881 & 38424.8 & $4.70 \mathrm{E}-03$ & $8.96 \mathrm{E}-02$ & 19.26 & 0.979 \\
\hline 4986.6 & 3.63E-02 & $8.10 \mathrm{E}-02$ & 17.41 & 0.885 & 39142.0 & $4.60 \mathrm{E}-03$ & $8.97 \mathrm{E}-02$ & 19.28 & 0.980 \\
\hline 5275.7 & $3.43 \mathrm{E}-02$ & $8.13 E-02$ & 17.48 & 0.889 & 39947.8 & $4.55 \mathrm{E}-03$ & $8.98 \mathrm{E}-02$ & 19.30 & 0.981 \\
\hline 5491.5 & 3.29E-02 & $8.17 \mathrm{E}-02$ & 17.56 & 0.893 & 40460.7 & $4.50 \mathrm{E}-03$ & $8.98 \mathrm{E}-02$ & 19.30 & 0.981 \\
\hline 5735.5 & $3.15 \mathrm{E}-02$ & $8.19 \mathrm{E}-02$ & 17.61 & 0.895 & 40965.8 & 4.40E-03 & $8.99 \mathrm{E}-02$ & 19.33 & 0.983 \\
\hline 5992.0 & 3.02E-02 & $8.22 \mathrm{E}-02$ & 17.67 & 0.898 & 42423.3 & $4.30 \mathrm{E}-03$ & $9.00 \mathrm{E}-02$ & 19.35 & 0.984 \\
\hline 6242.6 & $2.90 \mathrm{E}-02$ & $8.24 \mathrm{E}-02$ & 17.71 & 0.901 & 34242.6 & $4.20 \mathrm{E}-03$ & צ.01E-02 & 19.37 & 0.985 \\
\hline 6470.1 & $2.80 \mathrm{E}-02$ & $8.25 \mathrm{E}-02$ & 17.73 & 0.902 & 43913.5 & 4.10E-03 & $9.01 \mathrm{E}-02$ & 19.37 & 0.985 \\
\hline 6724.5 & $2.69 \mathrm{E}-02$ & $8.27 \mathrm{E}-02$ & 17.78 & 0.904 & 44896.8 & $4.00 \mathrm{E}-03$ & $9.02 \mathrm{E}-02$ & 19.39 & 0.986 \\
\hline 6977.1 & $2.59 \mathrm{E}-02$ & $8.29 \mathrm{E}-02$ & 17.82 & 0.906 & 46387.0 & $3.90 \mathrm{E}-03$ & $9.04 \mathrm{E}-02$ & 19.43 & 0.988 \\
\hline 7488.0 & $2.42 \mathrm{E}-02$ & $8.33 \mathrm{E}-02$ & 17.91 & 0.910 & 47846.4 & $3.80 \mathrm{E}-03$ & 9.05E-02 & 19.45 & 0.989 \\
\hline 7973.8 & $2.27 \mathrm{E}-02$ & 8.36E-02 & 17.97 & 0.914 & 49305.9 & $3.70 \mathrm{E}-03$ & $9.06 \mathrm{E}-02$ & 19.48 & 0.990 \\
\hline 8478.9 & $2.13 \mathrm{E}-02$ & 8.38E-02 & 18.01 & 0.916 & 50048.1 & 3.60E-03 & 9.07E-02 & 19.50 & 0.991 \\
\hline 8955.1 & $2.02 \mathrm{E}-02$ & $8.40 \mathrm{E}-02$ & 18.06 & 0.918 & 52762.6 & $3.40 \mathrm{E}-03$ & $9.09 \mathrm{E}-02$ & 19.54 & 0.993 \\
\hline 92.86 .7 & $1.95 \mathrm{E}-02$ & $8.42 \mathrm{E}-02$ & 18.10 & 0.920 & 54277.9 & $3.30 \mathrm{E}-03$ & $9.10 \mathrm{E}-02$ & 19.56 & 0.995 \\
\hline 9560.4 & $1.89 \mathrm{E}-02$ & $8.43 \mathrm{E}-02$ & 18.12 & 0.921 & 55729.6 & $3.20 \mathrm{E}-03$ & $9.11 \mathrm{E}-02$ & 19.58 & 0.996 \\
\hline \multirow{2}{*}{\multicolumn{2}{|c|}{$10030.81 .80 \mathrm{E}-02$}} & $8.45 \mathrm{E}-02$ & 18.16 & 0.923 & 57831.0 & $3.10 \mathrm{E}-03$ & $9.13 \mathrm{E}-02$ & 19.63 & 0.998 \\
\hline & & & & & 59811.0 & $3.00 \mathrm{E}-03$ & $9.15 \mathrm{E}-02$ & 19.67 & 1.000 \\
\hline
\end{tabular}

Useful equations:

Washburn ${ }^{1}$ suggested the use of mercury injection for measuring pore throat distributions in rocks. A common form of the Washburn equation is:

$$
P_{c}=\frac{-2 \gamma \cos \theta}{r} c
$$

or

$$
d=\frac{-4 \gamma \cos \theta}{P_{c}} c
$$

where $P_{c}$ is the capillary pressure in dynes $/ \mathrm{cm}^{2}, \gamma$ is the surface tension in dynes/cm, $\theta$ is the contact angle in degrees, $r$ is the radius of pore aperture assuming a cylindrical pore in $\mathrm{cm}$, and $\mathrm{c}$ is a conversion factor $(0.145038)$ that is used when $P_{c}$ is in psi and $r$ is in $\mu \mathrm{m}$.

Typical $\gamma$ and $\theta$ values used in laboratory calculations for

\begin{tabular}{|c|c|c|}
\hline $\begin{array}{r}\text { Typical Values } \\
\text { Pre }\end{array}$ & $\begin{array}{l}\text { TABLE B2 } \\
\text { Used in Lab } \\
\text { ssure Calcula }\end{array}$ & $\begin{array}{l}\text { atory Capillary } \\
\text { ions }\end{array}$ \\
\hline Fluids & $\theta$, degrees & $\gamma$, dynes/cm \\
\hline Air-mercury & 130 & 485 \\
\hline Air-water & 0 & 72 \\
\hline Air-oil & 0 & 24 \\
\hline Oil-water & 30 & 48 \\
\hline
\end{tabular}
room temperature tests are given in Table B2. 
Results from air-mercury tests can be compared to those of other fluids using Eq. 1 and solving for the capillary pressures which would exist using the other fluids. To predict air-water results from air-mes cury data:

$$
\text { Pcair-water }=\frac{(\gamma \cos \theta) \text { air-water }}{(\gamma \cos \theta) \text { air- } \mathrm{Hg}}\left(\mathrm{P}_{\mathrm{c}} \text { air- } \mathrm{Hg}\right)
$$

Various results calculated from mercury intrusion data can be plotted to emphasize pore throat distribution characteristics, such as cumulative intrusion versus diameter, incremental intrusion versus diameter, differential intrusion versus diameter, and log differential intrusion versus diameter. $\log$ differential intrusion is calculated as:

Log differential intrusion, $\mathrm{mL} / \mathrm{g}=\frac{-\left(I_{i}-I_{j-1}\right)}{\log r_{i}-\log r_{i-1}}$ where $I_{i}$ is the intrusion volume for the 1 th point $\left(\mathrm{Vin}_{\mathbf{i}}\right.$ Vin $n_{-1}$ from table $A 1$ ) and $r_{j}$ is the radius of a pore aperture at i point.

\section{Porous Plate Air-brine Measurements on Plug 4953B}

A porous plate capillary pressure test was conducted using plug 4953B. The plug was saturated with brine $(2 \%$ $\mathrm{KCl}$ by weight in water) and was placed in a pressure vessel on a porous plate of 65 psig air entry pressure. Brine volumes produced versus nitrogen pressure were recorded as the nitrogen gas pressure surrounding the sample was incrementally increased to 60 poig. Stabilization times at each point were from 3 to 6 days. Table B3 lists results from the test. The pore volume of the plug was $2.559 \mathrm{~cm}^{3}$.

TABLE B3

\begin{tabular}{|c|c|c|c|}
\hline Air-Brine Porous & late Capillary Pressure Results & For Plug 4959b & \\
\hline Nitrogen pressure, psig & Cumulative water produced $\mathrm{mL}$ & $\overline{\mathbf{S w}}$ & fraction \\
\hline 2.06 & 0.39 & & 0.848 \\
\hline 4.18 & 0.41 & & 0.840 \\
\hline 4.625 & 0.46 & & 0.820 \\
\hline 8.00 & 0.57 & & 0.777 \\
\hline 8.00 & 0.74 & & 0.711 \\
\hline 12.2 & 1.08 & & 0.578 \\
\hline 15.2 & 1.22 & & 0.523 \\
\hline 20.0 & 1.29 & & 0.496 \\
\hline 20.0 & 1.45 & & 0.433 \\
\hline 30.0 & 1.65 & & 0.355 \\
\hline 40.0 & 1.75 & & 0.316 \\
\hline 43.0 & 1.78 & & 0.304 \\
\hline 51.0 & 1.81 & & 0.293 \\
\hline 60.0 & 1.83 & & 0.285 \\
\hline
\end{tabular}


Centrifuge Capillary Pressure and

Wettability Measurements

\section{Centrifuge Oil-brine Measurements}

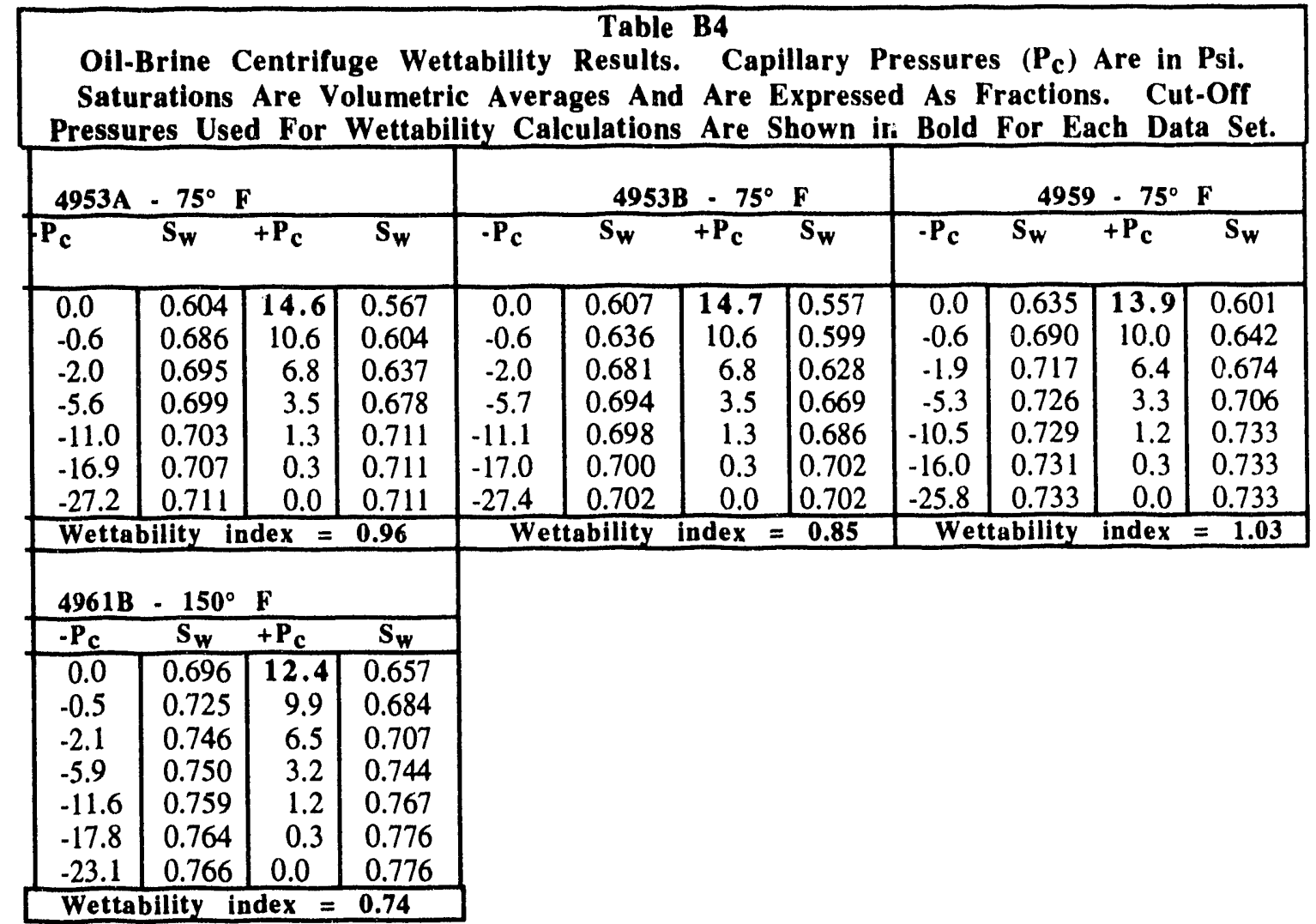

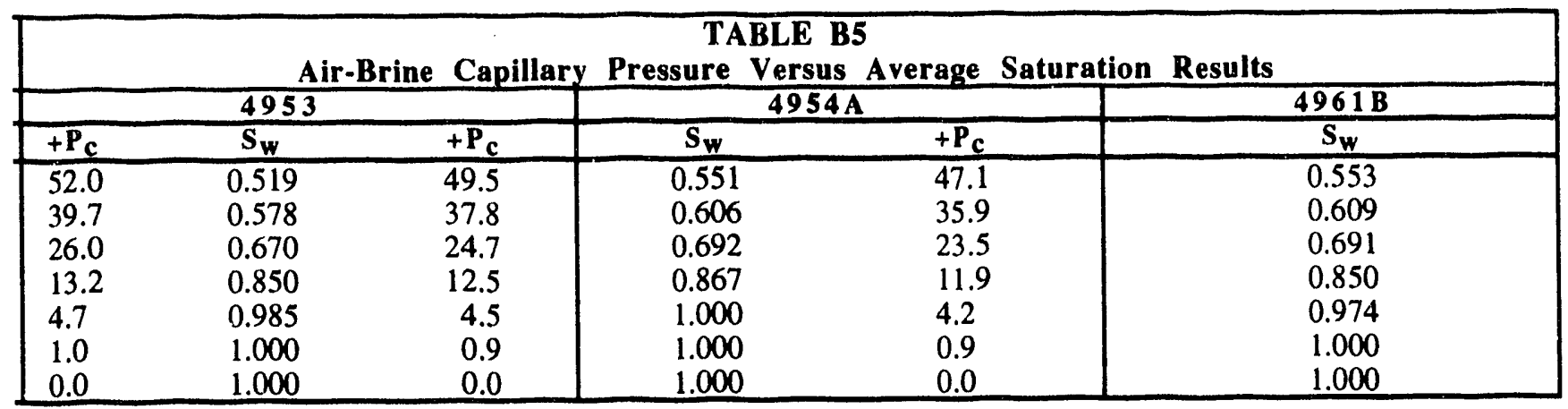

\section{Hassler-Brunner Capillary Pressure Versus End-Face Saturation Results}

Capillary pressure versus face saturation results were calculated using a Hassler-Brunner technique. For both imbibition and drainage cycles, the product of capillary pressure and the average saturation of the displaced-fluid were plotted versus the average saturation of the displaced fluid. These plots were then curve-fitted with double exponentials of the form

$$
y=a+b^{*} e^{(c x)}+d^{*} e^{(g x)}
$$

where $y$ represents the product of capillary pressure and average saturation, $x$ represents the average saturation, and $a, b, c, d$, and $g$ are constants for the best fit. Using the Hassler-Brunner approximation, the inlet oil saturations during the brine-displacing-oil cycle are given by

$$
S_{\text {oil,inlet }}=d y / d x=d\left(P_{c} * S_{\text {oil, average }}\right) / d P_{c}
$$

where $P_{c}$ represents the negative capillary pressures induced during the brine-displacing-oil cycle. Likewise, the inlet brine saturations during the oil-displacing-brine cycle are 
S brine, inlet $=d y / d x=d\left(P_{c} * S_{\text {orine, average }}\right) / d P_{c}$

where $P_{C}$ represents the positive capillary pressures induced during the oil displacing brine cycle.

\section{Correction of Elevated-Temperature Centrifuge Test Data for Density Effects}

Saturations calculated from elevated-temperature centrifuge test data will be in error unless the results are corrected for thermal effects. Fluid volumes produced from the test rock during each saturation cycle must be corrected for temperature-dependent volume changes that take place when the fluids are heated or cooled. Corrections depend upon the saturation conditions of the rock, the type of surrounding fluid, and the direction of temperature change (positive or negative).

Figure B1 is a diagram depicting thermally induced saturation changes that occur during an oil/brine wettability experiment on a water-wet rock. The o (oil) and $w$ (water) letters in the top left-hand corner of each figure represent the surrounding fluids. Below each figure, the + or $-\Delta \mathrm{T}$ indicates whether the temperature is increasing or decreasing. The diagram was constructed assuming that different centrifuge tubes are used for the $+\mathrm{Pc}$ (oildisplacing-water or drainage for a water-wet rock) and - $\mathrm{Pc}$ (water-displacing-oil or imbibition for a water-wet rock) centrifuge cycles. During the $+\mathrm{Pc}$ cycle, centrifuge tubes with graduations at the end away from the center of rotation are used because the produced fluid (brine) is normally denser than the surrounding fluid. Tubes with graduations at the end closest to the center of rotation are used during -Pc cycles because the produced fluid (oil) is usually less dense than the surrounding fluid. When one Pc cycle is completed, the rock and fluids are cooled to the laboratory temperature before the plug is ransferred to the tube for the next saturation cycle.

Initially, a brine-saturated rock is placed in an oil-filled centrifuge tube for the first $+\mathrm{Pc}$ cycle. The plug and fluids are heated to the test temperature. Expansion of the rock with temperature is usually negligible compared to expansion of the test fluids. As the plug is heated to the test temperature, a certain mass of brine is expelled because of thermal expansion (Fig. 1A). The volume that this mass of brine occupies should be subtracted from the brine $+\mathrm{Pc}$ production data to calculate correct saturations. Otherwise, calculated water saturation values from the first + Pc cycle will be lower than actual saturations.

At the end of the first +Pc cycle, the plug and fluids are cooled to room temperature while surrounded by oil (Fig. 1B). Additional oil is taken into the rock as the brine and oil inside the rock cool and contract. The plug is placed into another centrifuge tube and is surrounded by brine in preparation for the $-\mathrm{Pc}$ cycle. The plug and fluids are heated to the test temperature (Fig. 1C). Since the rock is at a residual brine saturation condition, one expects a volume of oil (not brine) to be expelled because of thermal expansion of the oil and brine within the plug. This volume should be subtracted from the - $\mathrm{Pc}$ oil production data because it is an excess volume rather than a volume produced because of centrifugal force.

Upon completing the -Pc cycle, the plug is cooled to room temperature. As the rock cools, the pore fluids contract and additional brine (the surrounding fluid) enters the rock. The plug is placed in an oil-filled $+\mathrm{Pc}$ tube and is heated to the test temperature for the second $+\mathrm{Pc}$ cycle. One would expect the same mass of brine that enters the the rock as it cools (Fig. 1D) to be expelled as the rock is heated (Fig. 1E). Finally, upon completing the $+\mathrm{Pc}$ cycle, the rock is cooled to the lab temperature. Additional oil, the surrounding fluid, is pulled into the rock as the temperature drops and the pore fluids contract (Fig. IF).

It is important to note that, as the rock is heated from room temperature to the test temperature, often there isn't any volume of the thermally expelled fluid in the graduated portion of the centrifuge tube until the spinning process begins. One explanation is that some or all of the fluid expelled from the rock by thermal expansion clings to the rock surface until the centrifuge rotation gives it an incentive to move into the graduated portion of the tube. The rock isn't visible when the tubes are in the tube holders and centrifuge buckets. After the tubes begin to spin, it is impossible to visibly distinguish whether fluids were expelled because of the temperature change or from the centrifuge rotation, so corrections must be applied considering fluid density changes with temperature and knowing which fluid is most likely expelled or imbibed as the result of a change in temperature. To maintain consistency, the volume expelled by thermal expansion that is calculated using the densities of the fluids at room and test temperatures (the thermal expansion of the rock can be neglected) is subtracted from all measured volumes out in that particular cycle. The potential error incurred using this method should be taken into account when interpreting elevated temperature centrifuge wettability results. Saturation changes that occur as the brine saturated rock is heated and as the rock cools at the end of centrifuge cycles (Figs. 1A, B, D, and F) are highly predictable since these saturation changes are governed by the thermodynamics of the system. Saturation changes that occur when the partially saturated rock is reheated (Fig. IC and E) may also be influenced by the rock wettability characteristics and it might be possible to have some of the fluid which is at a residual saturation condition expelled as the rock is heated. 


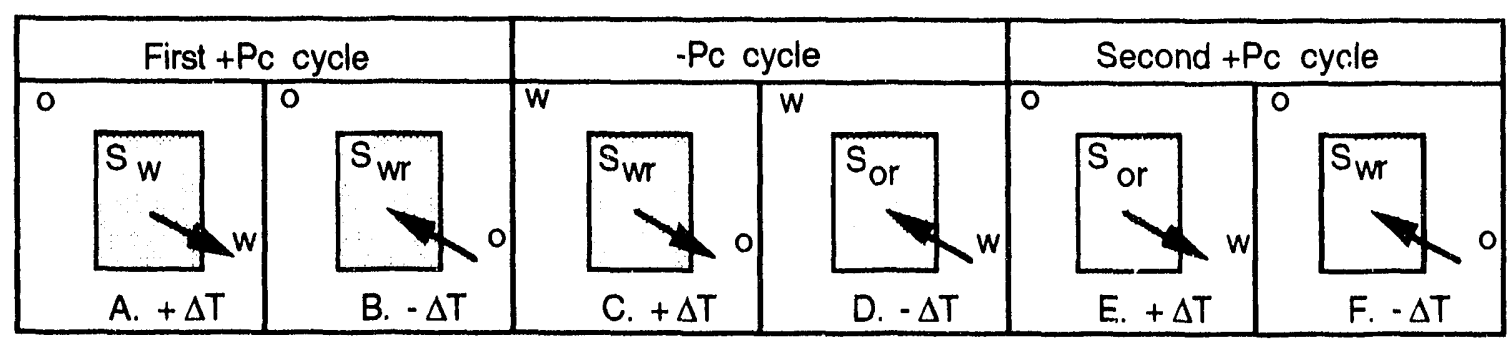

Fig. B1 Thermally induced nuid volume changes during elevated temperature centrifuge tests with a water-wet rock.

Ordinarily during tests at elevated temperatures, the oil volume produced at the first centrifuge speed during the $-\mathrm{Pc}$ cycle and the brine volume produced with the first speed during the second $+\mathrm{Pc}$ cycle are greater than or equal to the volumes expected to be displaced from fluid expansion calculations. Occasionally, however, if the plug is highly oil-wet, the first measured volume of oil in the -Pc cycle will be less than the volume expected to be thermally displaced. A possible explanation is that some brine is thermally displaced as well as some oil. From a limited number of tests, this phenomenon has only been observed for capillary pressures less than about 1 psi. A similar phenomenon has also been observed for highly water-wet samples at the beginning of the second + Pc cycle. With these water-wet samples, the volume of brine liberated from the plugs at the first centrifuge speed during the $+\mathrm{Pc}$ test is less than the volume predicted to thermally expand from the rock. This suggests that the water volume within the rock increased as the brine expanded and both oil and brine (rather than brine only) were liberated from the rock. During the $+\mathrm{Pc}$ cycle measurements, the rock is surrounded with oil, so oil produced from the rock is not observed. These phenomena are inferred from test results when the brine or oil volumes produced during measurements at the lowest centrifuge speed are less than the volumes of brine or oil expected from fluid expansion.
Another possibility is that because the brine or oil strongly wets the rock, volumes which thermally expand out of the rock adhere to the outer rock surface and don't break away until some critical capillary pressure is exceeded. Whatever the correct explanation, the calculated fluid volume expelled because of fluid expansion, as already described, is subtracted from all measured volumes expelled in that cycle. Correlations among wettability characteristics and these phenomena are still under investigation.

\section{Recommendations}

Corrections for fluid volumes produced because of thermal expansion are fairly simple and straightforward as long as the densities of the fluids are well defined at both the test temperature and at the laboratory temperature. It is very important to allow the plug and fluids to come to thermal equilibrium at either the lab temperature or the test temperature before recording data and before moving the rock from one centrifuge tube to the next.

\section{References}

1. Washburn, E., Note On a Method of Determining the Distribution of Pore Sizes in a Porous Material, Proc. of the National Academy of Science, v. 7, 115-116. 


\section{APPENDIX C RELATIVE PERMEABILTY AND SATURATION DATA}

Relative Permeability Test Data

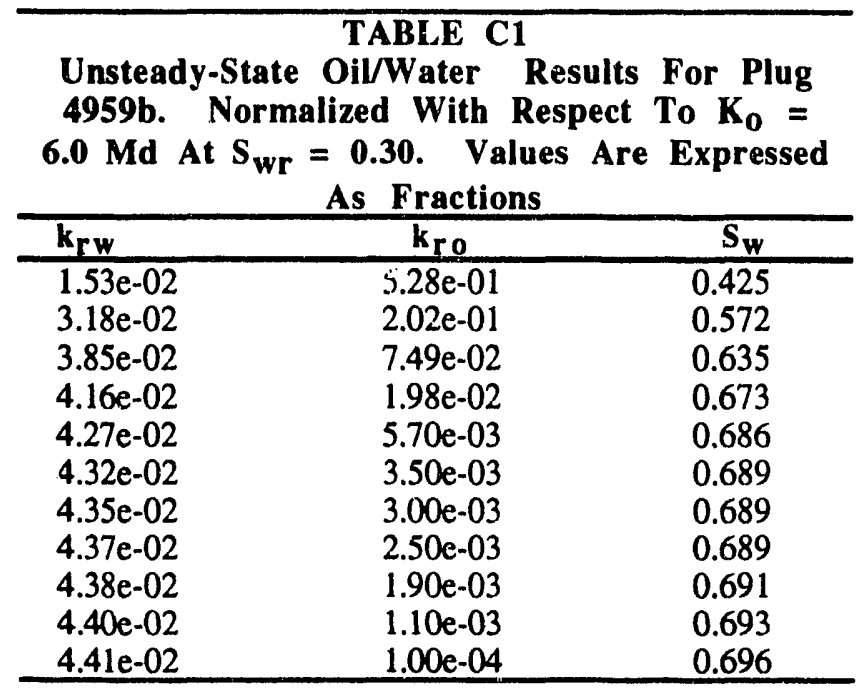

\begin{tabular}{|c|c|c|c|}
\hline \multicolumn{4}{|c|}{$\begin{array}{c}\text { TABLE C3 } \\
\text { Oil/Brine Relative Permeability Results. } \\
\text { Normalized With Respect To } \\
K_{W}=5.78 \text { Md At } S_{W}=1.000 \text {. Values Are } \\
\text { Expressed As Fractions }\end{array}$} \\
\hline$k_{r w}$ & $k_{\text {ro }}$ & $\mathbf{S}_{\mathbf{w}}$ & \\
\hline $8.13 \mathrm{E}-01$ & $5.61 \mathrm{E}-01$ & $\begin{array}{l}1.000 \\
0.440\end{array}$ & \\
\hline $\begin{array}{l}6.75 \mathrm{E}-03 \\
1.23 \mathrm{E}-02 \\
1.63 \mathrm{E}-02 \\
1.93 \mathrm{E}-02 \\
2.58 \mathrm{E}-02 \\
3.96 \mathrm{E}-02\end{array}$ & $\begin{array}{l}3.58 \mathrm{E}-01 \\
1.45 \mathrm{E}-01 \\
4.58 \mathrm{E}-02 \\
1.94 \mathrm{E}-02 \\
3.11 \mathrm{E}-03\end{array}$ & $\begin{array}{l}0.515 \\
0.610 \\
0.630 \\
0.634 \\
0.642 \\
0.690\end{array}$ & $\overline{\mathrm{i}}$ \\
\hline $\begin{array}{l}2.79 \mathrm{E}-02 \\
2.16 \mathrm{E}-02 \\
1.56 \mathrm{E}-02 \\
8.20 \mathrm{E}-03 \\
3.30 \mathrm{E}-03\end{array}$ & $\begin{array}{l}3.11 \mathrm{E}-03 \\
2.73 \mathrm{E}-02 \\
5.43 \mathrm{E}-02 \\
1.07 \mathrm{E}-01 \\
3.37 \mathrm{E}-01 \\
4.79 \mathrm{E}-01\end{array}$ & $\begin{array}{l}0.684 \\
0.642 \\
0.642 \\
0.579 \\
0.546 \\
0.506\end{array}$ & $\overline{\mathrm{d} 2}$ \\
\hline
\end{tabular}

\section{TABLE C2}

Gas/Water Relative Permeability Results. Normalized With Respect To

$K_{W}=5.78 \mathrm{Md}$ At $S_{W}=1.000$. Values Are Expressed As Fractions

\begin{tabular}{lcll}
\hline $\mathbf{k}_{\mathbf{r w}}$ & $\mathbf{k}_{\mathbf{r} q}$ & $\mathbf{S}_{\mathbf{w}}$ \\
\hline & $1.87 \mathrm{E}+00$ & 0.000 & \\
$1.00 \mathrm{E}+00$ & & 1.000 & \\
\hline & $1.40 \mathrm{E}+00$ & 0.434 & $\mathrm{i}$ \\
$7.96 \mathrm{E}-03$ & $3.18 \mathrm{E}-01$ & 0.565 & \\
$1.57 \mathrm{E}-02$ & $1.51 \mathrm{E}-01$ & 0.605 \\
$2.32 \mathrm{E}-02$ & $1.00 \mathrm{E}-01$ & 0.635 & \\
$3.98 \mathrm{E}-02$ & $4.33 \mathrm{E}-02$ & 0.675 & \\
$7.25 \mathrm{E}-03$ & $5.22 \mathrm{E}-02$ & 0.688 & \\
$1.21 \mathrm{E}-01$ & $7.70 \mathrm{E}-03$ & 0.750 & \\
$3.29 \mathrm{E}-01$ & & 0.892 & \\
\hline $7.96 \mathrm{E}-02$ & $7.20 \mathrm{E}-03$ & 0.741 & $\mathrm{~d}$ \\
$4.39 \mathrm{E}-02$ & $3.54 \mathrm{E}-02$ & 0.697 & \\
$1.77 \mathrm{E}-02$ & $1.33 \mathrm{E}-01$ & 0.676 & \\
$9.62 \mathrm{E}-03$ & $1.76 \mathrm{E}-01$ & 0.636 & \\
$2.63 \mathrm{E}-03$ & $2.89 \mathrm{E}-01$ & 0.605 & \\
& $4.84 \mathrm{E}-01$ & 0.446 & \\
\hline
\end{tabular}


TABLE C4

Gas/oil two-phase relative permeability results. Normalized with respect to $k_{w}=5.78 \mathrm{mD}$ at $S_{w}=1.000$. Values are expressed as fractions.

\begin{tabular}{ccccc}
\hline $\begin{array}{c}\mathbf{k}_{\mathbf{r}} \mathbf{0} \\
\mathbf{S}_{\mathbf{W}}\end{array}$ & $\mathbf{k}_{\mathbf{r g}}$ & $\mathbf{S}_{\mathbf{0}}$ & $\mathbf{S}_{\mathbf{g}}$ & \\
\hline $1.92 \mathrm{E}-01$ & $3.53 \mathrm{E}-03$ & 0.312 & 0.300 & 0.388 \\
$1.45 \mathrm{E}-01$ & $1.00 \mathrm{E}-02$ & 0.326 & 0.321 & 0.353 \\
$4.46 \mathrm{E}-02$ & $3.76 \mathrm{E}-02$ & 0.310 & 0.327 & 0.363 \\
$3.48 \mathrm{E}-02$ & $1.83 \mathrm{E}-01$ & 0.300 & 0.391 & 0.309 \\
$1.77 \mathrm{E}-02$ & $3.20 \mathrm{E}-01$ & 0.317 & 0.459 & 0.224 \\
$3.74 \mathrm{E}-03$ & $4.90 \mathrm{E}-01$ & 0.324 & 0.510 & 0.165 \\
& $7.45 \mathrm{E}-01$ & 0.253 & 0.578 & 0.169 \\
\hline
\end{tabular}

\section{TABLE C5}

Three-phase relative permeability results. Normalized with respect to $k_{w}=5.78 \mathrm{mD}$ at $S_{w}=1.000$. Values are expressed as fractions.

\begin{tabular}{lccccc}
\hline $\mathbf{k}_{\mathbf{r} w}$ & $\mathbf{k}_{\mathbf{r} \mathbf{0}}$ & $\mathbf{k}_{\mathbf{r q}}$ & $\mathbf{S}_{\mathbf{w}}$ & $\mathbf{S}_{\mathbf{0}}$ & $\mathbf{S}_{\mathbf{q}}$ \\
\hline $2.82 \mathrm{e}-02$ & $1.82 \mathrm{e}-02$ & $1.49 \mathrm{e}-03$ & 0.665 & 0.271 & 0.065 \\
$1.93 \mathrm{e}-02$ & $1.21 \mathrm{e}-02$ & $1.54 \mathrm{e}-03$ & 0.647 & 0.275 & 0.078 \\
$2.05 \mathrm{e}-02$ & $1.14 \mathrm{e}-02$ & $1.52 \mathrm{e}-03$ & 0.653 & 0.280 & 0.066 \\
$1.75 \mathrm{e}-02$ & $3.74 \mathrm{e}-03$ & $4.74 \mathrm{e}-03$ & 0.605 & 0.200 & 0.195 \\
$1.52 \mathrm{e}-02$ & $3.74 \mathrm{e}-03$ & $7.30 \mathrm{e}-03$ & 0.621 & 0.295 & 0.084 \\
$1.38 \mathrm{e}-02$ & $9.41 \mathrm{e}-03$ & $1.24 \mathrm{e}-02$ & 0.605 & 0.311 & 0.083 \\
$1.33 \mathrm{e}-02$ & $8.79 \mathrm{e}-03$ & $1.87 \mathrm{e}-02$ & 0.578 & 0.235 & 0.187 \\
$1.28 \mathrm{e}-01$ & $1.55 \mathrm{e}-02$ & $8.65 \mathrm{e}-05$ & 0.764 & 0.165 & 0.071 \\
$7.80 \mathrm{e}-02$ & $1.08 \mathrm{e}-02$ & $2.09 \mathrm{e}-03$ & 0.769 & 0.152 & 0.079 \\
$5.29 \mathrm{e}-02$ & $6.22 \mathrm{e}-03$ & $3.07 \mathrm{e}-03$ & 0.684 & 0.142 & 0.174 \\
$5.61 \mathrm{e}-02$ & $7.44 \mathrm{e}-03$ & $2.82 \mathrm{e}-03$ & 0.697 & 0.163 & 0.140 \\
$4.57 \mathrm{e}-02$ & $6.82 \mathrm{e}-03$ & $2.66 \mathrm{e}-03$ & 0.666 & 0.187 & 0.147 \\
$3.76 \mathrm{e}-02$ & $3.48 \mathrm{e}-03$ & $2.42 \mathrm{e}-03$ & 0.679 & 0.188 & 0.133 \\
$4.34 \mathrm{e}-02$ & $5.38 \mathrm{e}-03$ & $3.03 \mathrm{e}-03$ & 0.685 & 0.187 & 0.128 \\
$4.30 \mathrm{e}-02$ & $2.02 \mathrm{e}-03$ & $3.01 \mathrm{e}-03$ & 0.665 & 0.160 & 0.176 \\
\hline
\end{tabular}

\section{Verification of $X$-ray and Microwave Saturation Measurements}

Tests were designed to verify the linearities of the X-ray and microwave techniques for in situ fluid saturation measurements. The tests were conducted by scanning a confined sample of Almond formation rock as fluids with different X-ray and microwave atienuation characteristics were injected. Several solutions of potassium iodide (KI) in $2 \%$ potassium chloride $(\mathrm{KCl})$ brine were used as test fluids for the $\mathrm{X}$-ray tests. The $\mathrm{X}$-ray results were expected to vary linearly with the $\mathrm{KI}$ concentration. This was true, as shown in Fig. $\mathrm{Cl}$. Brine diluted with various concentrations of glycerine were used as the test fluids during the microwave tests. Because microwave attenuation was mostly a function of water saturation in the brine/glycerine fluid system, microwave results (natural $\log$ of incident divided by emergent microwave power) were expected to vary linearly with the brine concentration. This was found to be true as shown in Fig. C2. The correlation coefficients for the best fit lines to the data sets on Fig. C1 were better than 0.99 . The correlation coefficients for the data of Fig. C2 were better than 0.98 . Tests such as these are valuable for verifying the accuracy of the $\mathrm{X}$-ray and microwave scanning techniques for measuring insitu fluid saturations.



Fig. C1 X-ray results versus weight percent of potassium lodide in brine. 


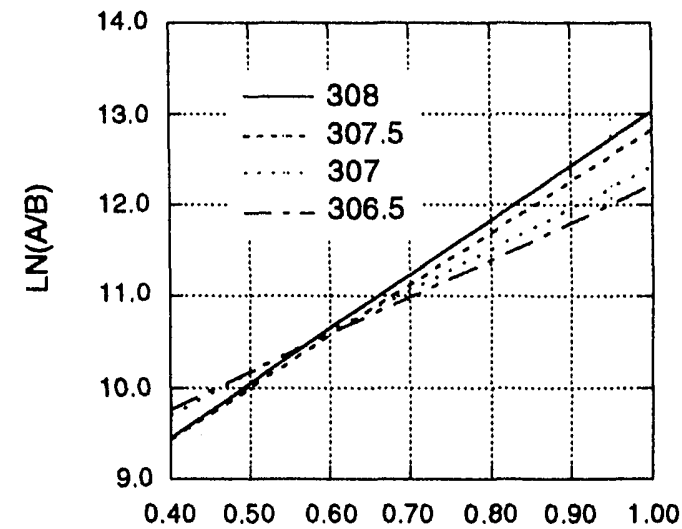

WATER FRACTION IN A GLYCERINEWATER SOLUTION

Fig. C2 Microwave results versus water fraction in a glycerine and water solution. 


\section{APPENDIX D RESERVOIR CONDITION MEASUREMENTS AND IMPROVEMENTS IN TEST SYSTEMS AND METHODOLOGIES}

\section{Capillary Tube Viscometer Design and Calibration}

\section{Summary}

It is important to have the capability of monitoring the viscosities of test fluids during reservoir condition relative permeability experiments. Changes in fluid viscosities during a test because of temperature fluctuations or other experimental conditions can lead to changes in pressure drop measurements which would otherwise be interpreted as being the result of changes in the rock permeability characteristics. A capillary tube viscometer was constructed in our laboratory to gain familiarity in the construction, calibration, and implementation of this simple viscosity-measurement device. Detaiis are provided in this appendix.

\section{Equipment}

A capillary tube viscometer was constructed using 610.6 $\mathrm{cm}$ of $0.1588 \mathrm{~cm}(1 / 16-\mathrm{inch})$ OD 316 stainless steel tubing.
The ID was measured to be $0.1145 \mathrm{~cm}$, suggesting a wall thickness of about $0.0222 \mathrm{~cm}$. To facilitate handling, the tubing was bent into a 2 -inch diameter coil. The viscometer was calibrated using Millipore ${ }^{\circledR}$ deionized water. A Validyne ${ }^{\circledR}$ transducer with a 1 psi diaphram was used to measure pressure drops across the coil. An Isco ${ }^{\circledR}$ pump was used to maintain constant liquid flowrates through the coil. A $200 \mathrm{~cm}^{3}$ reservoir was placed in front of the coil to ensure the liquid was at test temperature before flowing through the coil. A Blue $M^{\circledR}$ oven was used to provide a constant temperature environment. A Nupro $\otimes$ back-pressure regulator was initially used to keep the fluid in liquid state at high temperatures. Later, a Coretest Systems, Inc. DBRP 100 backpressure regulator which was modified for operation within the 50 to 500 psig range was substituted for the less-accurate Nupro. A two-channel Omega thermocouple readout was used in conjunction with two thermocouples to monitor the temperatures of the coil and reservoir. A diagram of the apparatus used is shown in Fig. D1.

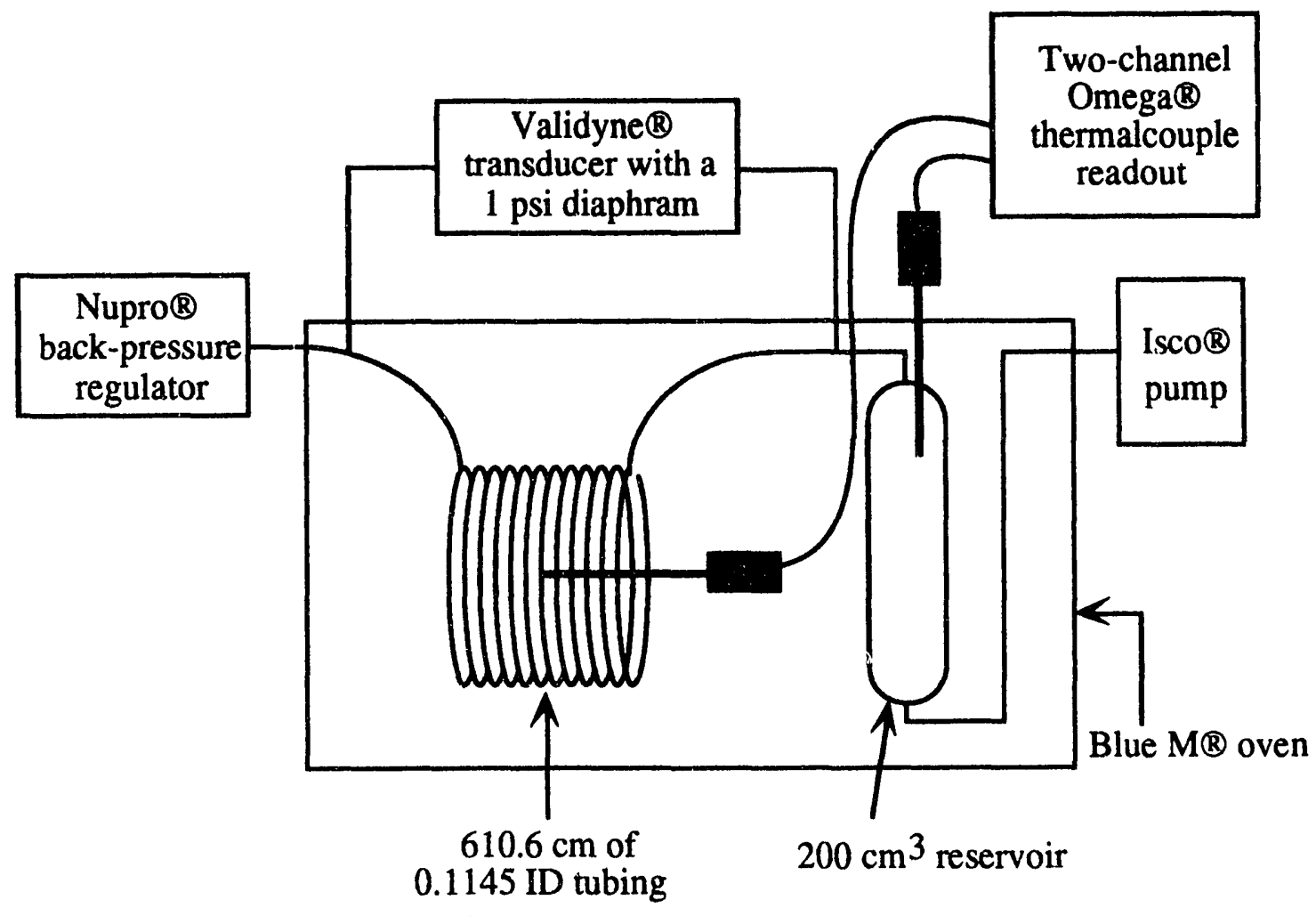

Fig. D1 Capillary tube viscometer apparatus. 


\section{Design Criteria}

For laminar fluid flow in a capillary tube, the HagenPoiseuille equation becomes

$$
\mu=\left(\pi \mathrm{D}^{4} / 128 \mathrm{~L}\right) *(\Delta \mathrm{P} / \mathrm{Q})
$$

where $\mu$ is the viscosity of the fluid, D is the I.D. of the tube, $L$ is the length of the tube, and $\Delta P$ is the differential pressure measured across the tube for a fluid flowrate $Q$. For $\mathrm{D}$ and $\mathrm{L}$ in units of $\mathrm{cm}, \Delta \mathrm{P}$ in $\mathrm{psi}$, and $\mathrm{Q}$ in $\mathrm{mL} / \mathrm{sec}$, Eq. D1 becomes

$$
\mu, c P=169222.9 *\left(D^{4} / L\right) *(\Delta P / Q)
$$

At $72^{\circ} \mathrm{F}, \Delta \mathrm{P}$ was measured at several flowrates to obtain an average $\triangle P / Q$ of $21.269 \mathrm{psi} /(\mathrm{mL} / \mathrm{sec})$ for deionized water. As the viscosity of water is known to be $0.950 \mathrm{cP}$ at $72{ }^{\circ} \mathrm{F}$ and the length of the capillary tube was $610.6 \mathrm{~cm}$, the Hagen-Poiseuille equation gives an effective inside diameter of $0.1127 \mathrm{~cm}$. This might suggest that there is a boundary layer of thickness $0.0009 \mathrm{~cm}$ inside the tube for which flow is negligible.

In general, flow through a tube is laminar provided the Reynold's number

$$
\operatorname{Re}=\rho \mathrm{VD} / \mu
$$

is less than 2,300 where $\rho$ is the fluid density, $V$ is the mean fluid velocity, $D$ is the inside diameter of the tube, and $\mu$ is the fluid viscosity. Reynold's number calculations can be performed to evauate whether the flow is laminar during a test. Our experiments were first conducted with deionized water. Temperatures to $300^{\circ} \mathrm{F}$ were anticipated. The maximum pump delivery rate was $0.05 \mathrm{~mL} / \mathrm{sec}(200$ $\mathrm{mL} / \mathrm{hr}$ ). Equation D3 was solved assuming conditions which yield the highest possible Reynold's number. Results were

$$
\begin{aligned}
& \mu_{\min }=0.2 \mathrm{cP}=0.2 \mathrm{e}-2 \mathrm{~g} /\left(\mathrm{cm}^{*} \mathrm{sec}\right) \\
& \rho_{\max }=1.2 \mathrm{~g} / \mathrm{cm}^{3} \\
& \mathrm{D}_{\max }=0.12 \mathrm{~cm} \\
& \mathrm{~V}_{\max }=Q_{\max } / A_{\max }=\left(0.05 \mathrm{~cm}^{3} / \mathrm{sec}\right) /\left(\pi *(0.05 \mathrm{~cm})^{2}\right)= \\
& \quad 6.37 \mathrm{~cm} / \mathrm{sec} \\
& \operatorname{Re}_{\max }=(1.2 * 6.37 * 0.12) /(0.2 \mathrm{e}-2) \\
& =459<2300 .
\end{aligned}
$$

According to this analysis with the maximum temperature and injection rates stated, the water flow should be laminar for all expected test situations using the capillary tube viscometer since the maximum Reynold's number is only 459.

\section{Calibration}

Calibration tests were conducted under constant temperature conditions. Pressure drops across the length of the capillary tube were measured as deionized water was injected at three or four different rates. Linear regression was then performed to determine an average $\Delta P / Q$. Tests were performed at nine temperatures in the range from $72^{\circ}$ to $313^{\circ} \mathrm{F}$. The data collected is shown in Table D1. A linear regression analysis was then performed to relate viscosity with $\triangle \mathrm{P} / \mathrm{Q}$ as is shown in Fig. D2. One can readily calculate an effective $D^{4} / L$ for the temperature range incurred using equation D2 and the slope of the linear regression curve fit.

TABLE D1

Viscosity and $\triangle \mathrm{P} / \mathrm{Q}$ Data

\begin{tabular}{rcc} 
T, ${ }^{\circ} \mathbf{F}$ & $\mu \mathbf{w}, \mathbf{c P}$ & $\begin{array}{c}\Delta \mathbf{P} / \mathbf{Q}, \\
\mathbf{p s i} /(\mathbf{m L} / \mathbf{s e c})\end{array}$ \\
\hline 72 & 0.9498 & 21.269 \\
99 & 0.6886 & 15.476 \\
147 & 0.4405 & 9.9693 \\
178 & 0.3498 & 7.9441 \\
222 & 0.2666 & 6.1405 \\
243 & 0.2383 & 5.5341 \\
260 & 0.2186 & 5.1115 \\
305 & 0.1823 & 4.4933 \\
313 & 0.1782 & 4.4527
\end{tabular}

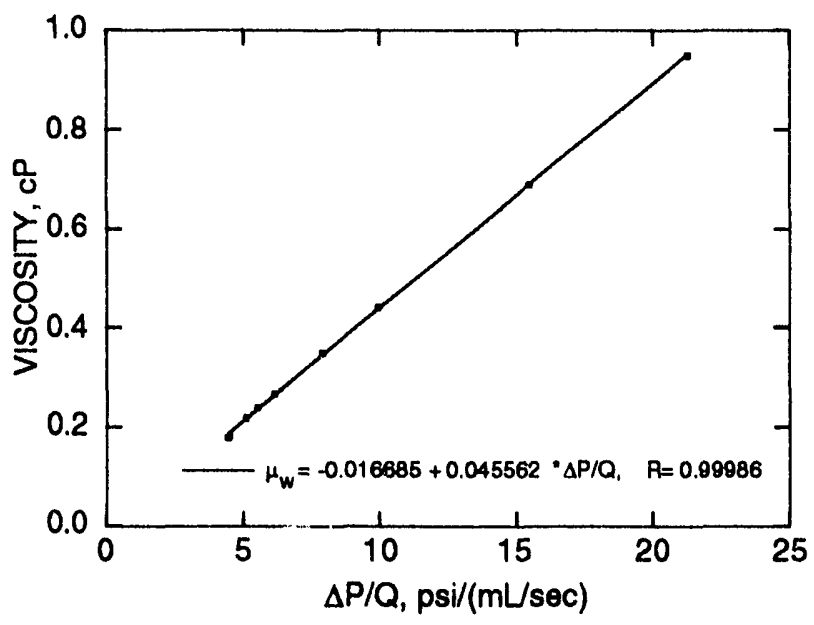

Fig. D2. Capillary tube viscometer temperature constants and empirical curve fit.

\section{Temperature Bath for Tests at Elevated Temperatures}

Methods for heating the multiphase steady-state permeameter were studied. Preliminary designs were completed for modifying an existing heating cabinet to accomodate the microwaveable coreholder and other associated hardware. The system will feature two compartments: one on the scanning table which houses 
the coreholder and a second below which houses transfer vessels, tubing, and other associated equipment. The $\mathrm{O}$ rings and other temperature sensitive parts within the microwave coreholder were replaced.

\section{Methods for Calibrating X-ray Attenuation to Fluid Saturations During Reservoir Condition Tests}

Tests were conducted using a Berea sandstone core plug to evaluate procedures for determining $\mathrm{X}$-ray calibrations during high-temperature experiments. The primary objective of these tests was to evaluate the effect of temperature changes on X-ray calibrations. Measurements were recorded at room temperature and at $280^{\circ} \mathrm{F}$. These temperatures were selected as the low and high limits for long term tests.

A dry Berea sandstone plug was inserted into a highpressure coreholder. The plug was confined with 4,000 psig confining pressure. Silicone oil was used as the hydraulic fluid to supply the confining pressure. An $X$-ray scan was taken of the dry rock. Next, the coreholder was heated to $280^{\circ} \mathrm{F}$ while the 4,000 psig confining pressure was maintained. Because the silicone oil expands when heated, the confining pressure was maintained at the 4,000 psig confining pressure by allowing the silicone oil to expand out of the coreholder through a 4,000 psig backpressure regulator. The $280^{\circ} \mathrm{F}$ dry rock was $\mathrm{X}$-ray scanned, then the coreholder was cooled to $74^{\circ} \mathrm{F}$. Additional silicone oil was pumped into the coreholder to maintain the 4,000 psig confining pressure as the oil cooled and contracted. The plug was saturated with brine tagged with sodium iodide at the $74^{\circ} \mathrm{F}$ temperature and was $\mathrm{X}$-ray scanned. An additional scan was taken after heating the coreholder back to the $280^{\circ} \mathrm{F}$ test temperature. Again, the 4,000 psig confining pressure was maintained.

Figure D3 shows the results from this investigation for three of the rock scan positions (with $1 \mathrm{~cm}$ spacing between positions). Table D4 shows the $X$-ray scan data and the difference between dry and saturated scans at each temperature. The X-ray data are expressed at the natural log of the X-ray intensity emergent from the coreholder. Changes in $\mathrm{X}$-ray intensity with changes in temperature resulted because the volume of silicone oil in the coreholder had to be reduced as the temperature increased in order to maintain a constant confining pressure. Figure D4 shows X-ray scan data that was recorded as the coreholder cooled to ambient temperature after one of the high temperature measurements. A similar plot would have resulted if the intensity was plotted against number of moles of silicone oil within the coreholder annular space.

TABLE D3

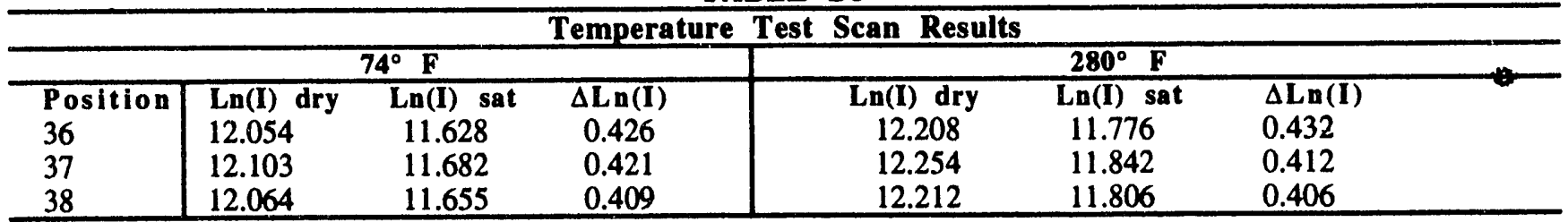

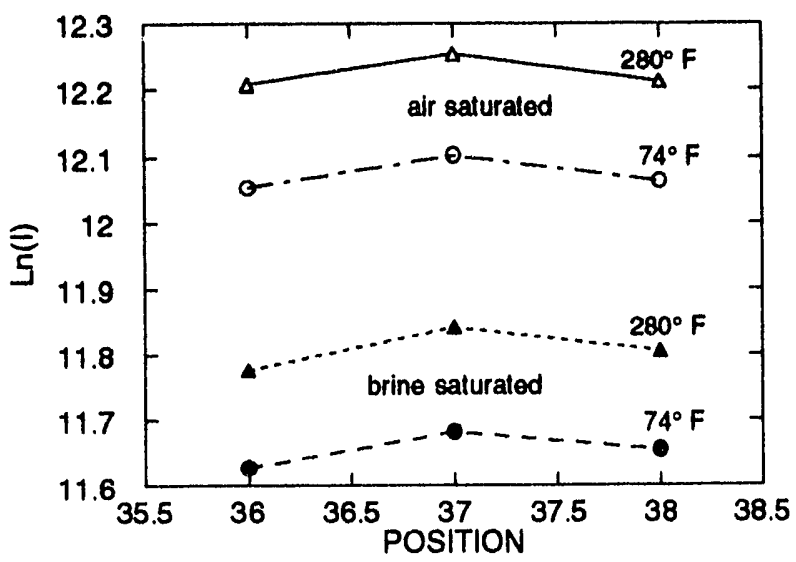

Fig. D3 Comparison of X-ray results at $74^{\circ} \mathrm{F}$ and $280^{\circ} \mathrm{F}$.

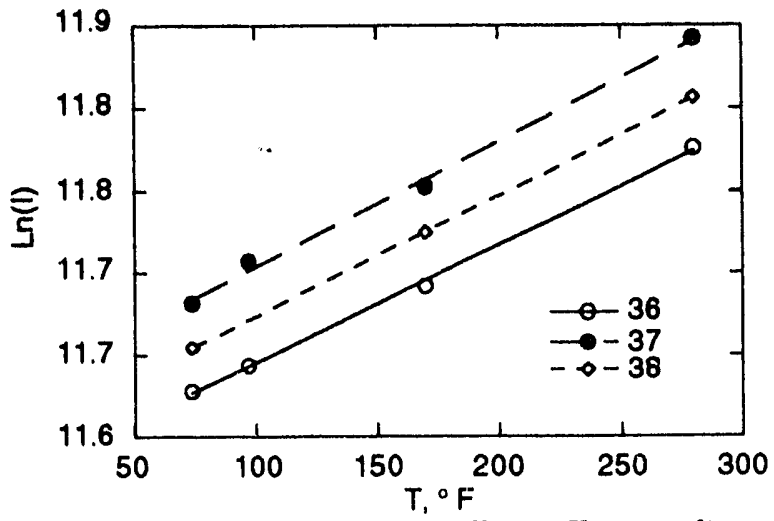

Fig. D4 Temperature effect on X-ray results.

These results demonstrate that calibration equations determined at room temperature can be translated to a 
higher temperature condition as long as one of the calibration scans is repeated at the higher temperature condition and as long as the density of the brine does not change significantly with temperature. Otherwise, a compensation for brine density changes should also be considered. This calibration technique will be useful for high temperature, high confining pressure tests in which the coreholder o-rings may not withstand several temperature/confining pressure cycles. 

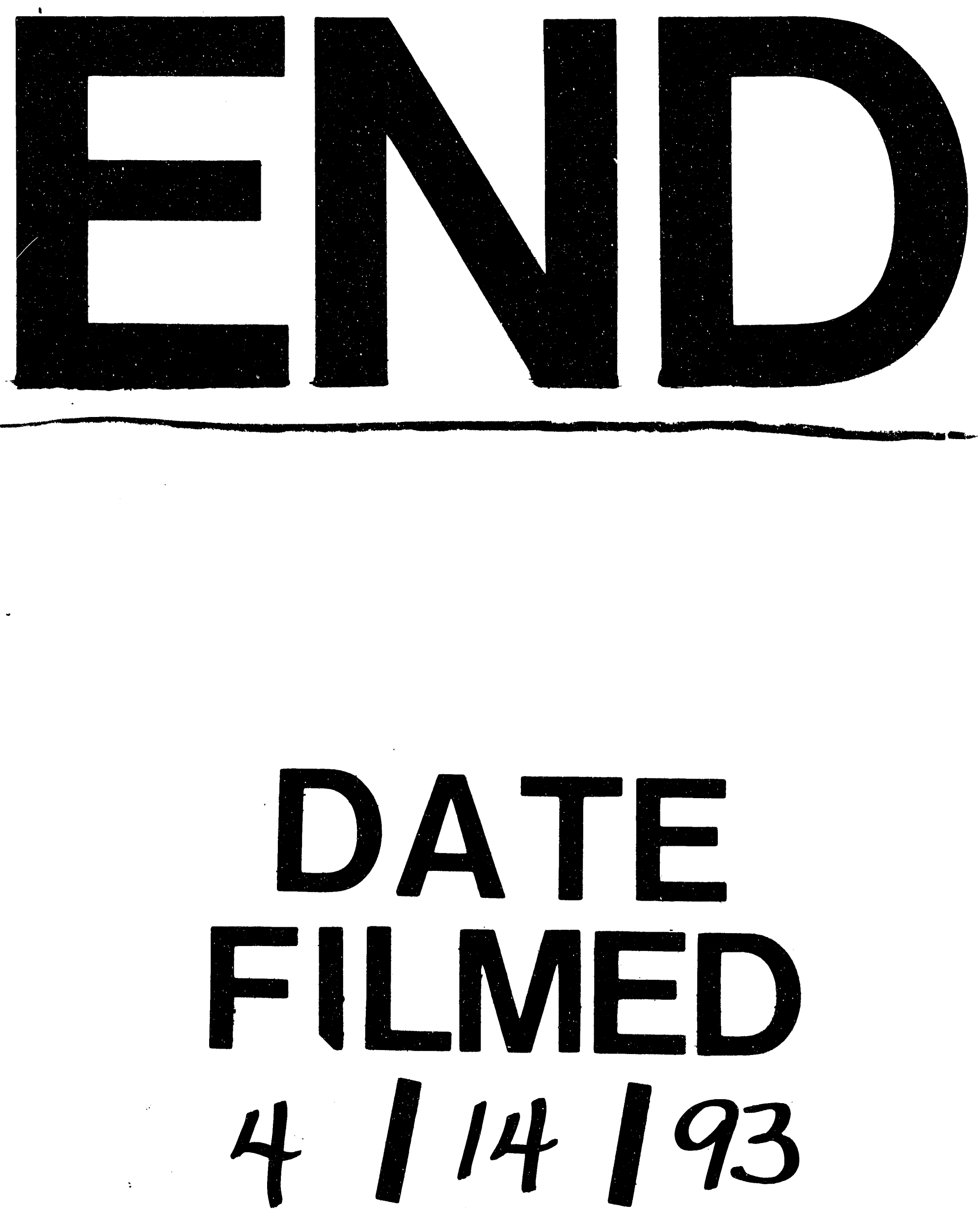
